\title{
Gender differences in the intention to get vaccinated against COVID-19: a systematic review and meta-analysis
}

\author{
Stephanie Zintel ${ }^{1}$. Charlotte Flock ${ }^{1} \cdot$ Anna Lisa Arbogast ${ }^{1} \cdot$ Alice Forster $^{2} \cdot$ Christian von Wagner $^{2}$. \\ Monika Sieverding ${ }^{1}$ (D)
}

Received: 6 May 2021 / Accepted: 11 November 2021

(c) The Author(s) 2022

\begin{abstract}
Aim We conducted a systematic review and meta-analysis to analyse gender differences in COVID-19 vaccination intentions. Subject and methods PubMed, Web of Science and PsycInfo were searched (November 2020 to January 2021) for studies reporting absolute frequencies of COVID-19 vaccination intentions by gender. Averaged odds ratios comparing vaccination intentions among men and women were computed. Descriptive analyses of the studies were reported.

Results Sixty studies were included in the review and data from 46 studies $(n=141,550)$ were available for meta-analysis. A majority (58\%) of papers reported men to have higher intentions to get vaccinated against COVID-19. Meta-analytic calculations showed that significantly fewer women stated that they would get vaccinated than men, OR 1.41 (95\% CI 1.28 to 1.55). This effect was evident in several countries, and the difference was bigger in samples of health care workers than in unspecified general population samples.

Conclusion This systematic review and meta-analysis found lower vaccination intentions among women than men. This difference is discussed in the light of recent data on actual vaccination rates in different countries.
\end{abstract}

Keywords Covid-19 $\cdot$ Vaccination intention $\cdot$ Gender differences $\cdot$ Health care workers $\cdot$ Systematic review $\cdot$ Meta-analysis

\section{Introduction}

The COVID-19 pandemic is among the greatest challenges of today's time. As of mid October 2021, more than 236 million people have already been infected with SARS-CoV-2 with 4.8 million deaths worldwide (WHO 2021). Several vaccines have been approved (Zimmer et al. 2021) and after initial supply shortfalls, vaccination rates accelerated as of spring 2021. In high-income countries, vaccination rates with at least one dose varied between $60 \%$ and $80 \%$ by mid-October 2021 (Ritchie et al. 2021). In developing countries where supply with vaccines is scarce, vaccination rates are much lower, for example 52\% in India and under $10 \%$ in most parts of Africa (Ritchie et al. 2021). It has

Monika Sieverding

monika.sieverding@psychologie.uni-heidelberg.de

1 Department of Psychology, Ruprecht Karls University Heidelberg, Hauptstr. 47-51, 69117 Heidelberg, Germany

2 Research Department of Behavioural Science and Health, University College London, 1-19 Torrington Place, London WC1E 6BT, UK been estimated that considering now dominating vaccines, vaccination rates of $85-95 \%$ are necessary to protect from a severe increase of infections (Weber et al. 2021).

Next to availability of vaccines, the intention to get vaccinated against COVID-19 is regarded as a key variable for predicting actual vaccination uptake; it has been shown in a meta-analysis that health-related intentions are causally linked to the respective health-related behaviours (Webb and Sheeran 2006). A high availability of vaccination doses is a necessary but not sufficient prerequisite of actual vaccination uptake. If intentions are too low in the general population or in specific subgroups, the success of a COVID-19 vaccination campaign is seriously threatened.

In this paper, we are interested in COVID-19 vaccination intentions as a function of gender. Research on other vaccines showed gender differences in vaccination status and intentions favouring men (Bish et al. 2011) which may transfer to the COVID-19 vaccine. Some early surveys also reported lower COVID-19 vaccination intentions among women (Galanis et al. 2020; Lin et al. 2021; Robinson et al. 2020). Lower vaccination intentions among women could be problematic for various reasons. Next to exposing 
themselves to the danger of a COVID-19 infection, women have a central role in ensuring the health of their children. Additionally, women are more likely to be health and social care workers who are at high risk of contracting and passing on COVID-19.

Before vaccines against COVID-19 were approved and vaccination programs started, worldwide surveys were undertaken to assess individuals' intentions to get vaccinated against COVID-19 in the general population and among samples of health care workers (HCWs). The main goal of our study was to review and analyse the results of these surveys, investigating whether there are systematic gender differences in the intention to get vaccinated against COVID-19.

\section{Method}

\section{Search strategy}

The initial search was conducted on 19.11.2020 in PubMed, Web of Science and PsycInfo. We used the search terms (vaccination OR vaccine OR vaccinated) AND (corona OR coronavirus OR SARS-CoV-2 OR COVID-19) in combination with 'refusal', 'hesitancy', 'hesitance', 'hesitation', 'acceptance', 'willingness', 'motivation', 'confidence', 'uptake', 'intention', 'attitude', 'emotion', 'opinion', 'trust', 'doubts', 'cognition', 'rejection', 'disapproval', 'belief'. This search identified 649 articles on PubMed, 192 on Web of Science and 17 on PsycInfo. We filtered results for the year 2020 to 2021 (because the global COVID-19 outbreak happened in 2020) and in PubMed for languages English or German. We used a method described by Bramer et al. (2016) to identify duplicates. The final number of articles for screening was 682.

We identified 26 papers reporting gender specific data on vaccination intentions in any sort. We manually conducted a forward and backward citation search of those 26 papers. In this way, we identified a further 18 papers that reported gender data on vaccination intentions. Data extraction can be seen in Fig. 1.

After the initial search, we regularly checked data bases for new publications. Inclusions based on these searches can be seen in Fig. 1. The last search was conducted the 7th of January 2021 on all three databases. Subsequently we wrote to the authors $(N=50)$ who did not report the data needed for meta-analytic calculations in their articles. Lastly, we had to exclude 19 papers for various reasons. ${ }^{1}$

\footnotetext{
${ }^{1}$ Sixteen papers were only excluded from meta-analytic calculations due to the authors not providing us with the necessary data. Three papers were completely excluded. One was a preprint-version of a published article we already included, another one reported an outcome item for vaccination intention that included questions about
}

\section{Eligibility and exclusion criteria}

The search results were screened for inclusion following these eligibility criteria: Primarily adult population, reported outcome: intention/willingness to get vaccinated against COVID-19 for men and women separately or gender differences statistically tested, available in English or German. Cross-sectional and longitudinal studies were included. Studies reporting an interventional/experimental design were excluded from our analysis (see Fig. 1 for study selection).

\section{Data analysis}

Apart from looking at studies descriptively, we conducted meta-analytic calculations of averaged odds ratios. For this calculation, we first computed odds ratios using the exact frequency statistics reported in the papers or provided by the authors upon request. We made two different types of calculation: We compared 'yes'-answers (including 'definitely yes'- and 'probably yes'-answers and similar answer options) with the remaining 'non-yes' answer categories which could also include 'do not know'- or 'not sure'-answers (in Table 1: YR, frequencies for yes vs. rest categories reported). We additionally compared 'yes'-answers (including 'definitely yes'- and 'probably yes'-answers and similar answer options) with 'no'-answers (including 'definitely' or 'probably no'-answers and similar answer options, in Table 1: YN, frequencies for yes vs. no categories reported). For the meta-analytical calculations, we included 46 studies which provided the necessary data for the 'yes'- versus 'nonyes' answers and used the metafor package in $\mathrm{R}$ described by Viechtbauer (2010) to compute mean gender effects of summarized odds ratios and confidence intervals. We also conducted a meta-analysis that was based on a smaller number of 40 studies which provided the necessary data for the 'yes'- versus 'no' -answers. The results of this additional meta-analysis can be found in the Supplemental Material. We used a random effects model for our meta-analysis due to heterogeneity in our samples that (widely) differed in dimensions such as residence, age, and profession. As a result, we cannot assume that the effect estimates vary only because of chance differences from sampling participants, in which case a fixed-effect model is indicated (Riley et al. 2011). Restricted maximum likelihood estimation was used to fit a

\section{Footnote 1 (continued)}

the assumptions that the COVID-19 vaccination would be a good way to protect oneself and therefore differed too widely from the usually used vaccination intention item. The last one was a preliminary report of a study not properly analysed yet (and only reported gender differences for a specific age group). 
Fig. 1 PRISMA flow diagram showing the study selection process

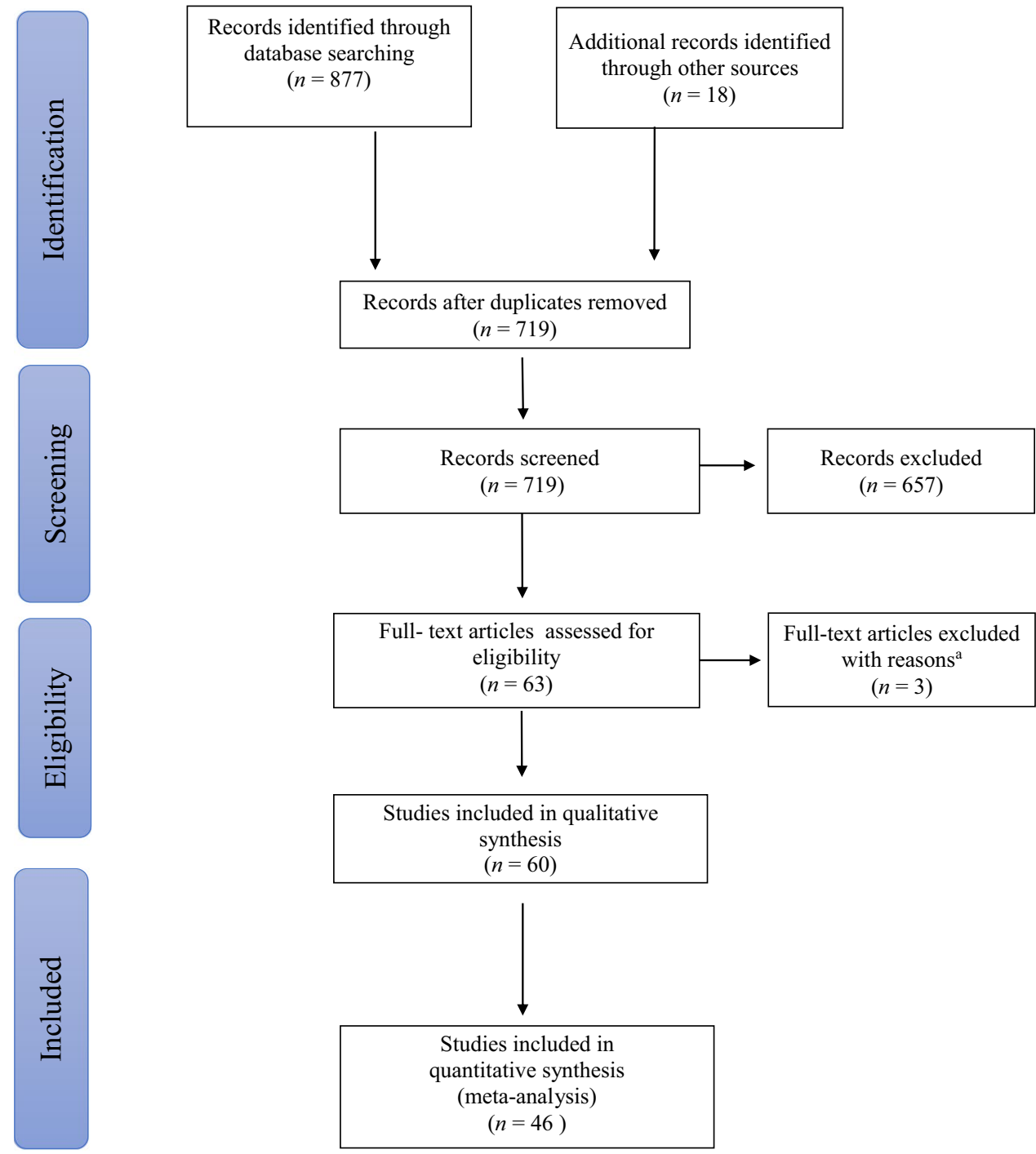

Note. ${ }^{\mathrm{a} O n e}$ was a preprint version of a reviewed paper already included, one assessed vaccination intention inappropriately and one was excluded due to quality reasons.

random-effects model to the data respectively as estimator to compute the heterogeneity $\tau^{2}$. In the meta-analysis, we used moderator analyses to determine if the effects of the studies differed depending on quality appraisal, month of assessment or being a healthcare worker or not (variable $\mathrm{HCW}$ ). If recruitment took place over several months, the first month was coded. HCWs were chosen as a subgroup because it was the only group addressed by several studies. Knapp and Hartung adjustment was used to lower type I error rates (IntHout et al. 2014) and can be seen as a good replacement of the standard method (Jackson et al. 2017). Representativeness of samples was not used as a separate moderator because it was included in the quality rating. Owing to the rapidly evolving situation, it was not surprising that many papers were available as preprints which is unlikely to reflect the quality of research. For quality appraisal, we used the suitable aspects of already established tools as there were no comprehensive quality assessment tools that fitted for the survey studies. More detailed information can be found in the Supplementary Material. We adhered to PRISMA guidelines in the preparation and realization of our review.

\section{Results}

\section{Description of the studies}

Sample sizes, sampling techniques, countries and month of assessment, publication type, item wording for the variable of interest, as well as quality ratings and reported gender differences can be seen in Table 1. Sample sizes ranged from 128 (Grech et al. 2020a) to 32,361 (Paul et al. 2020) 


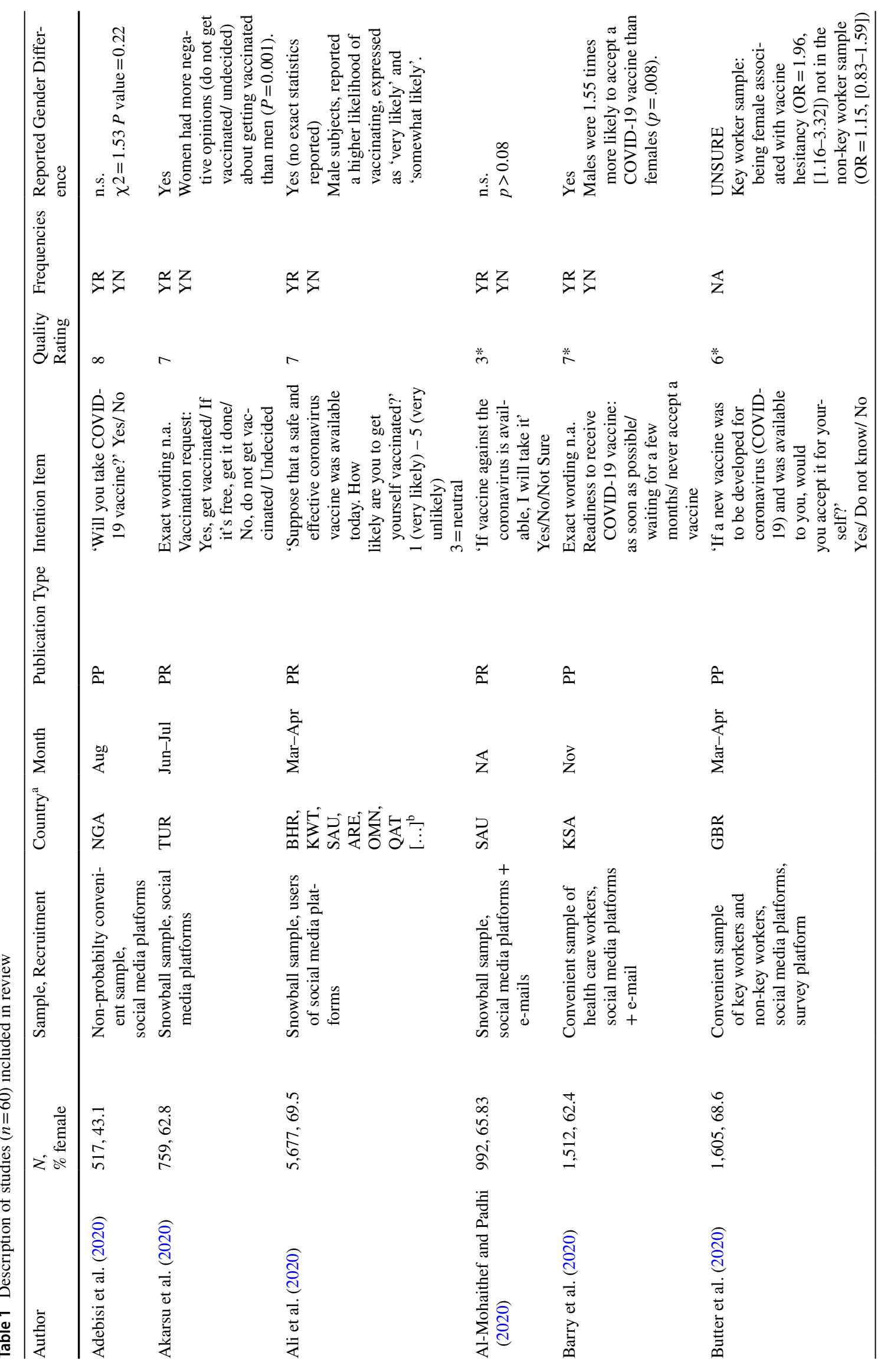




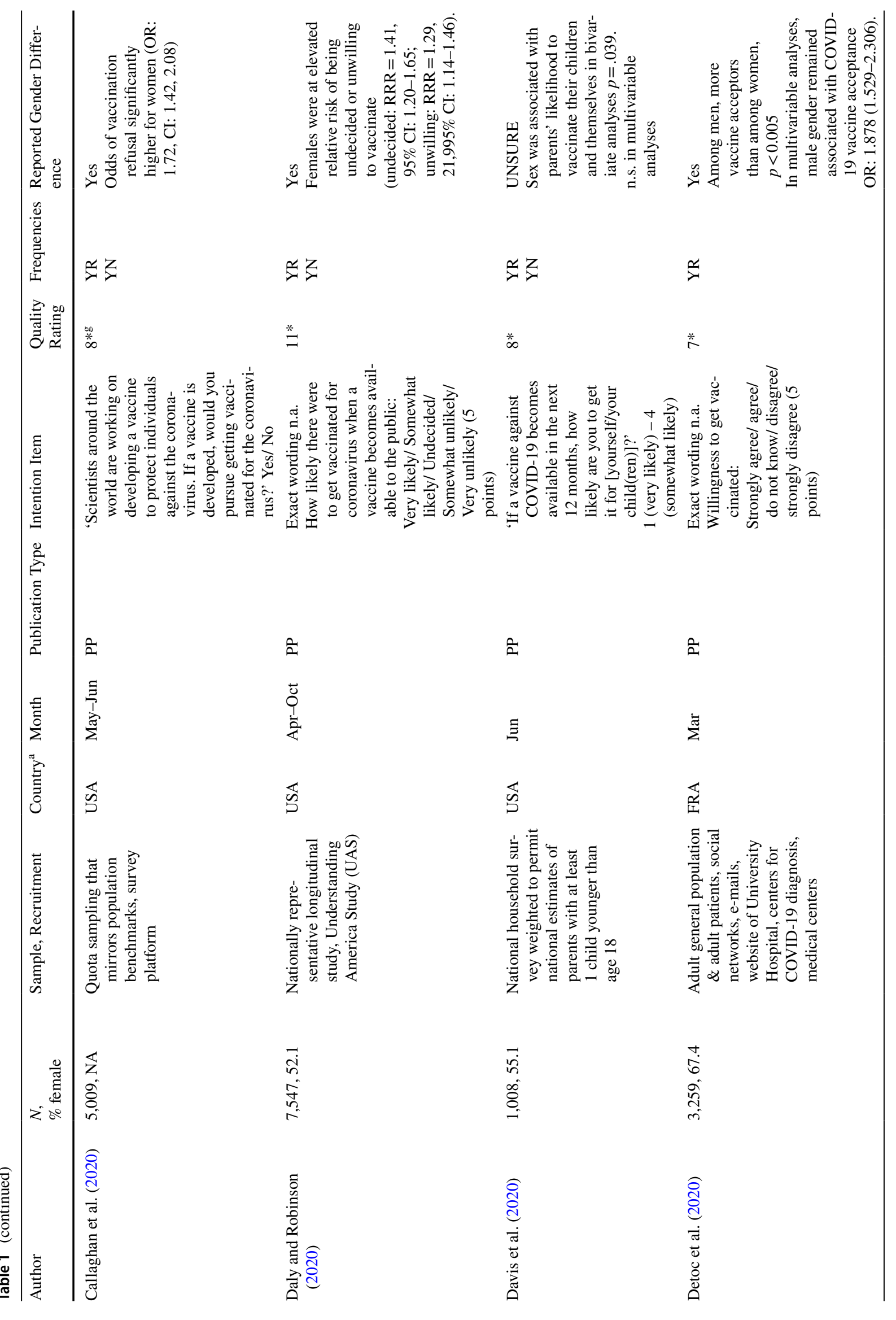




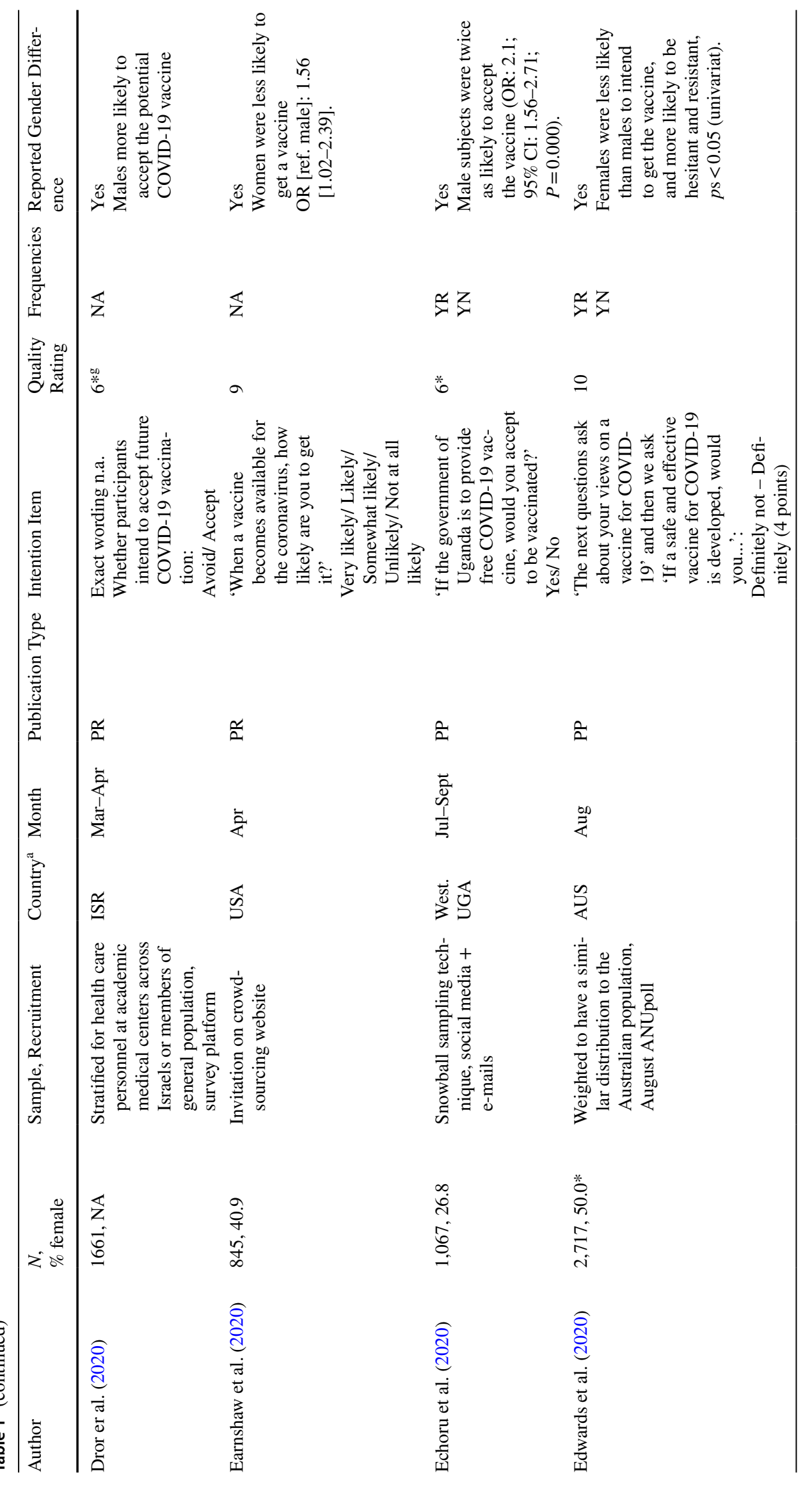




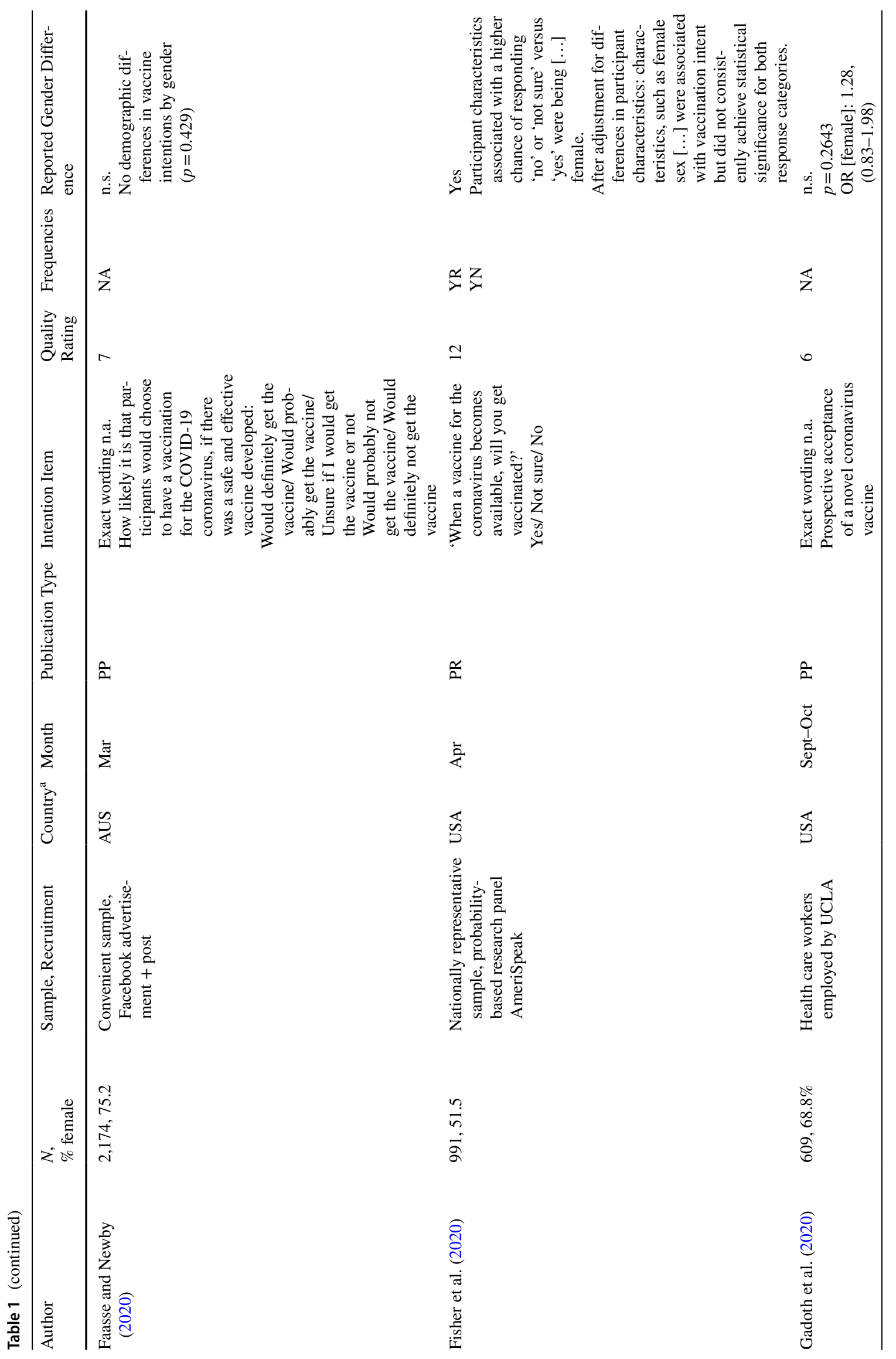




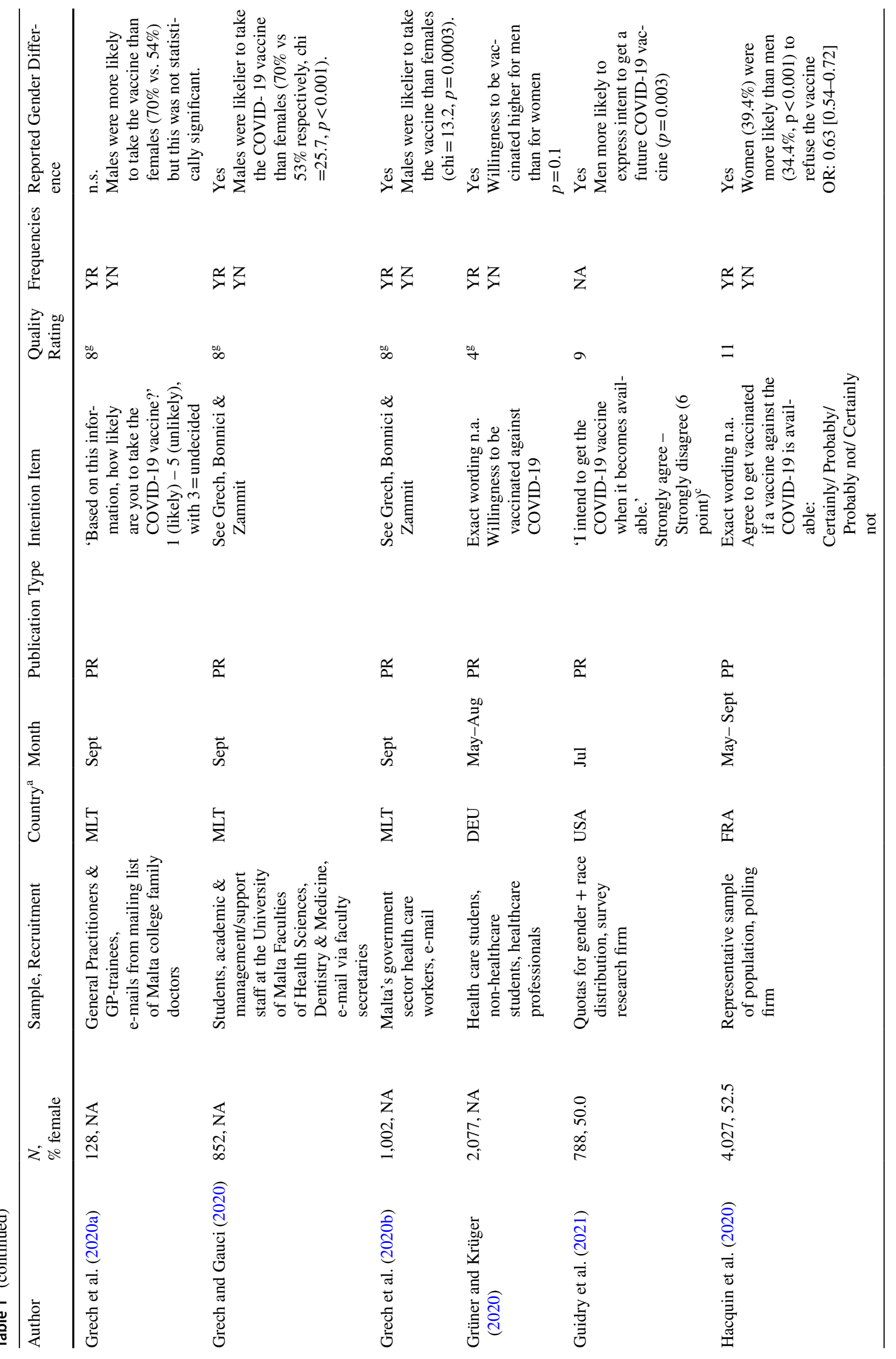




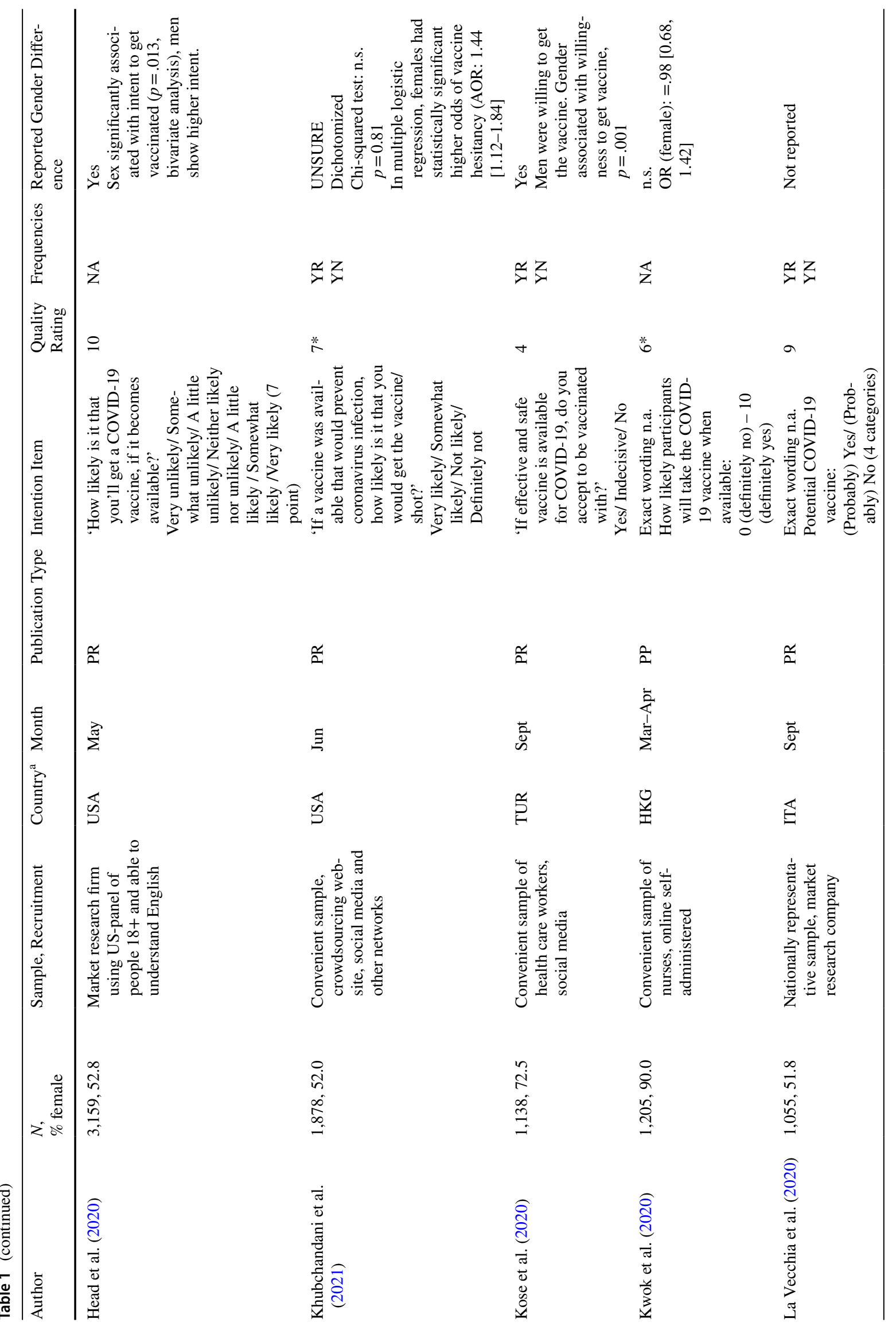




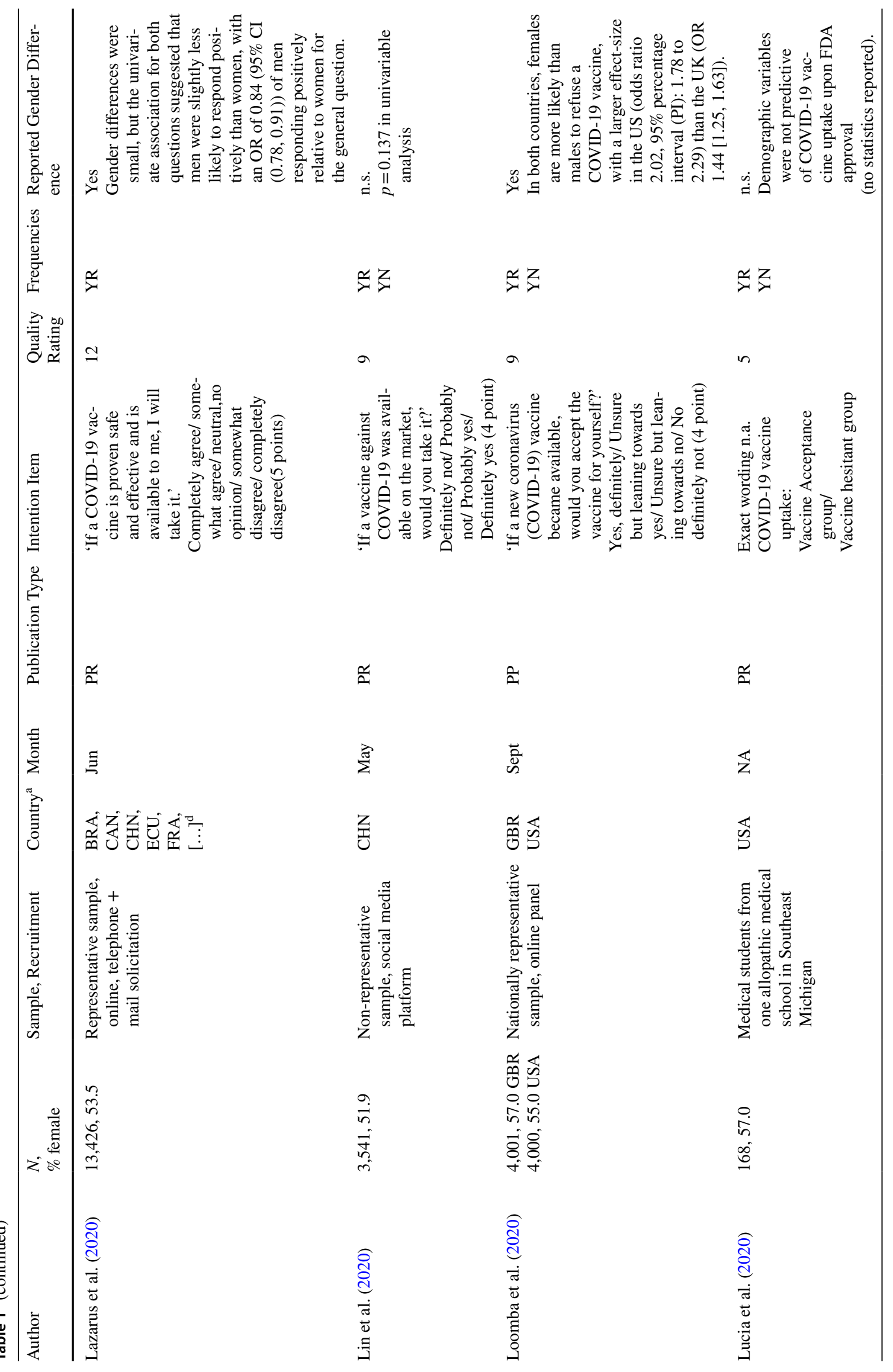




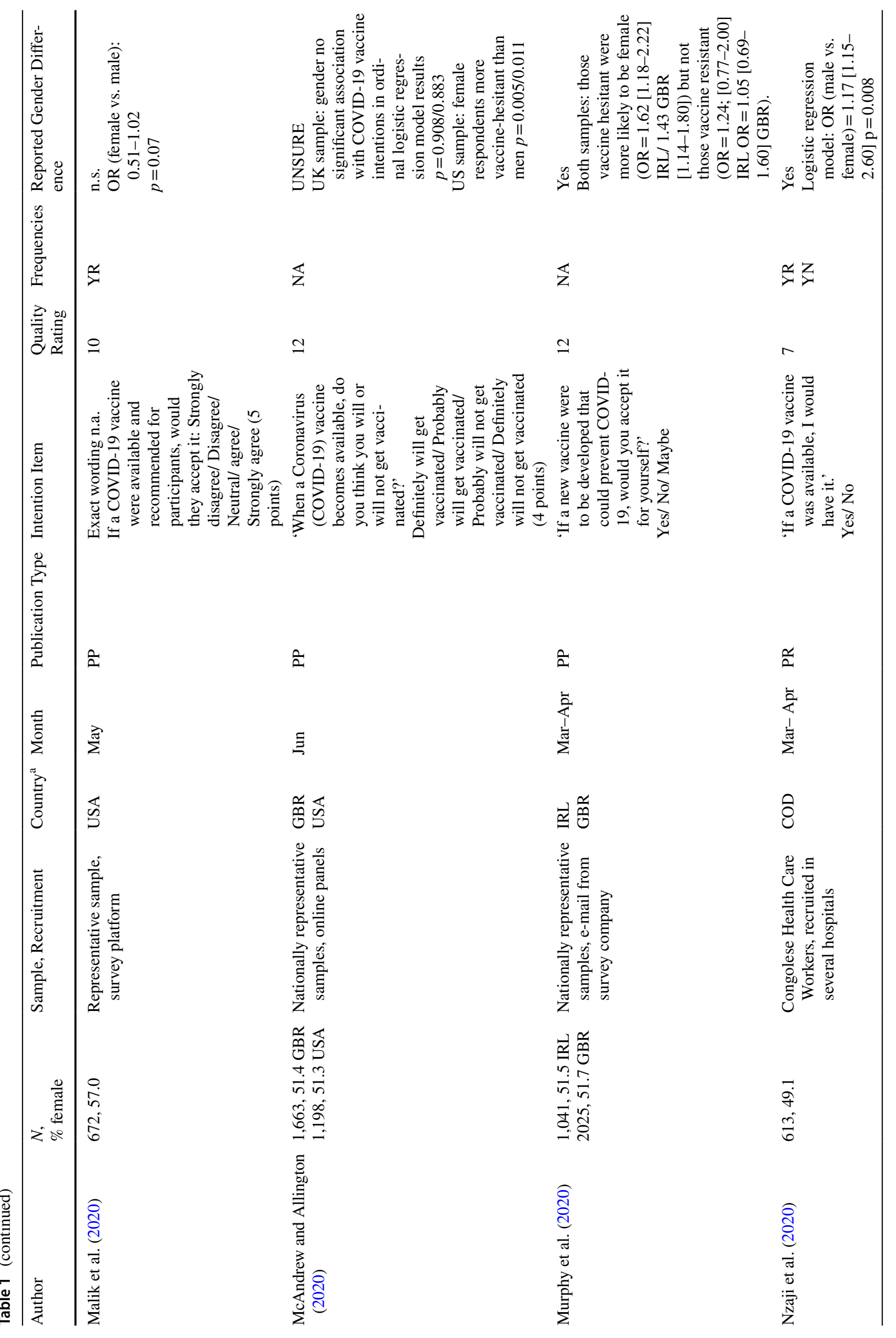




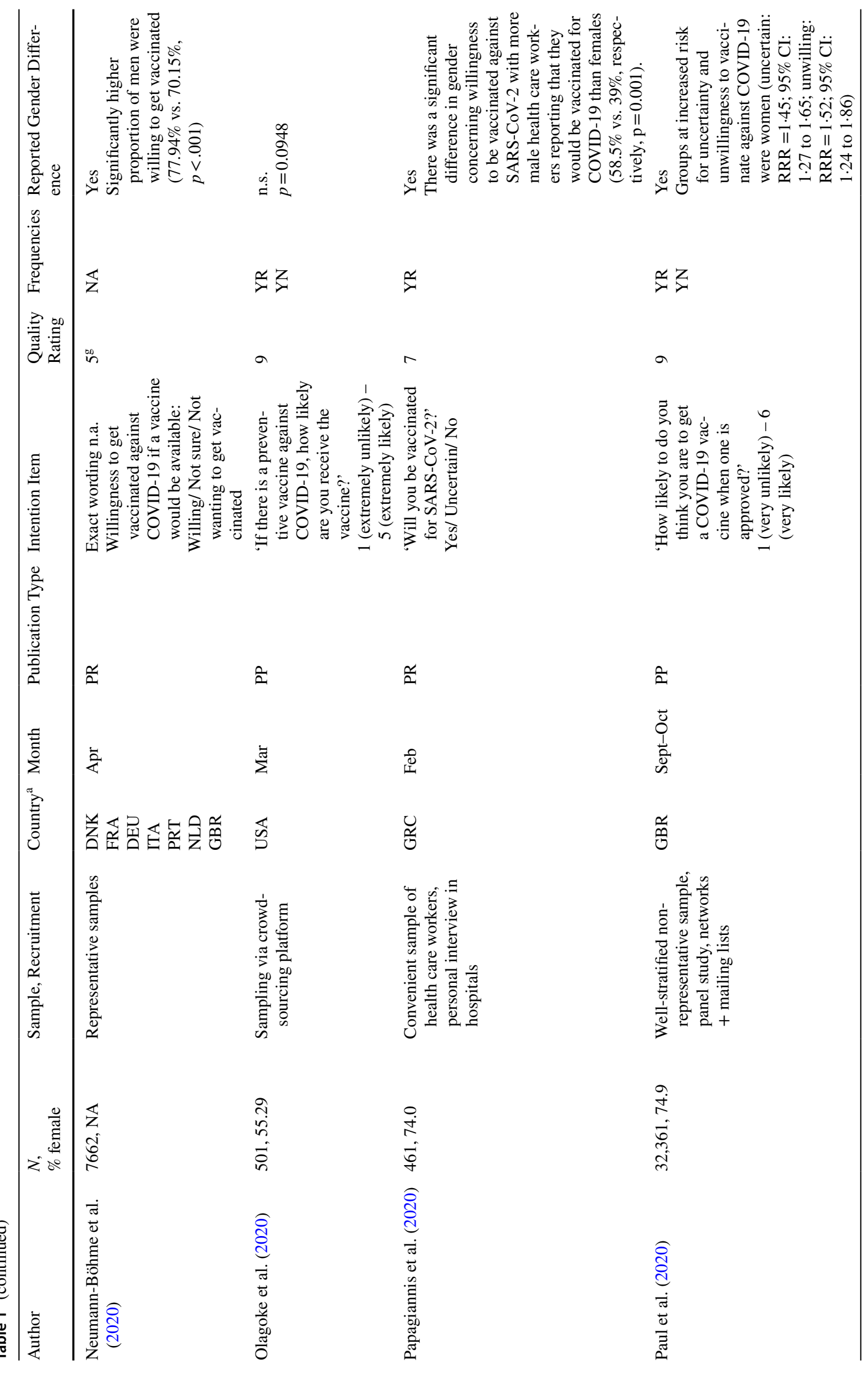




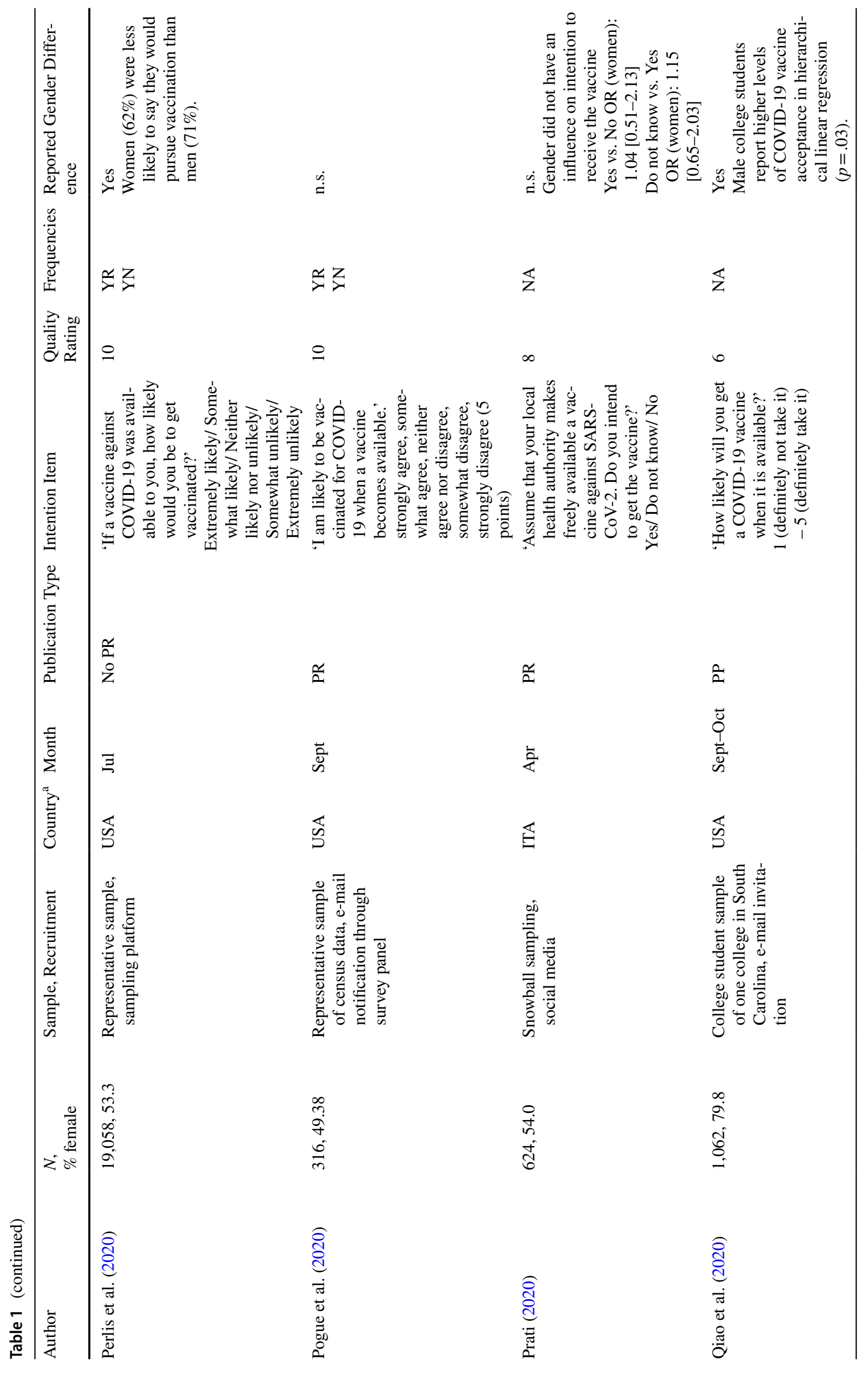




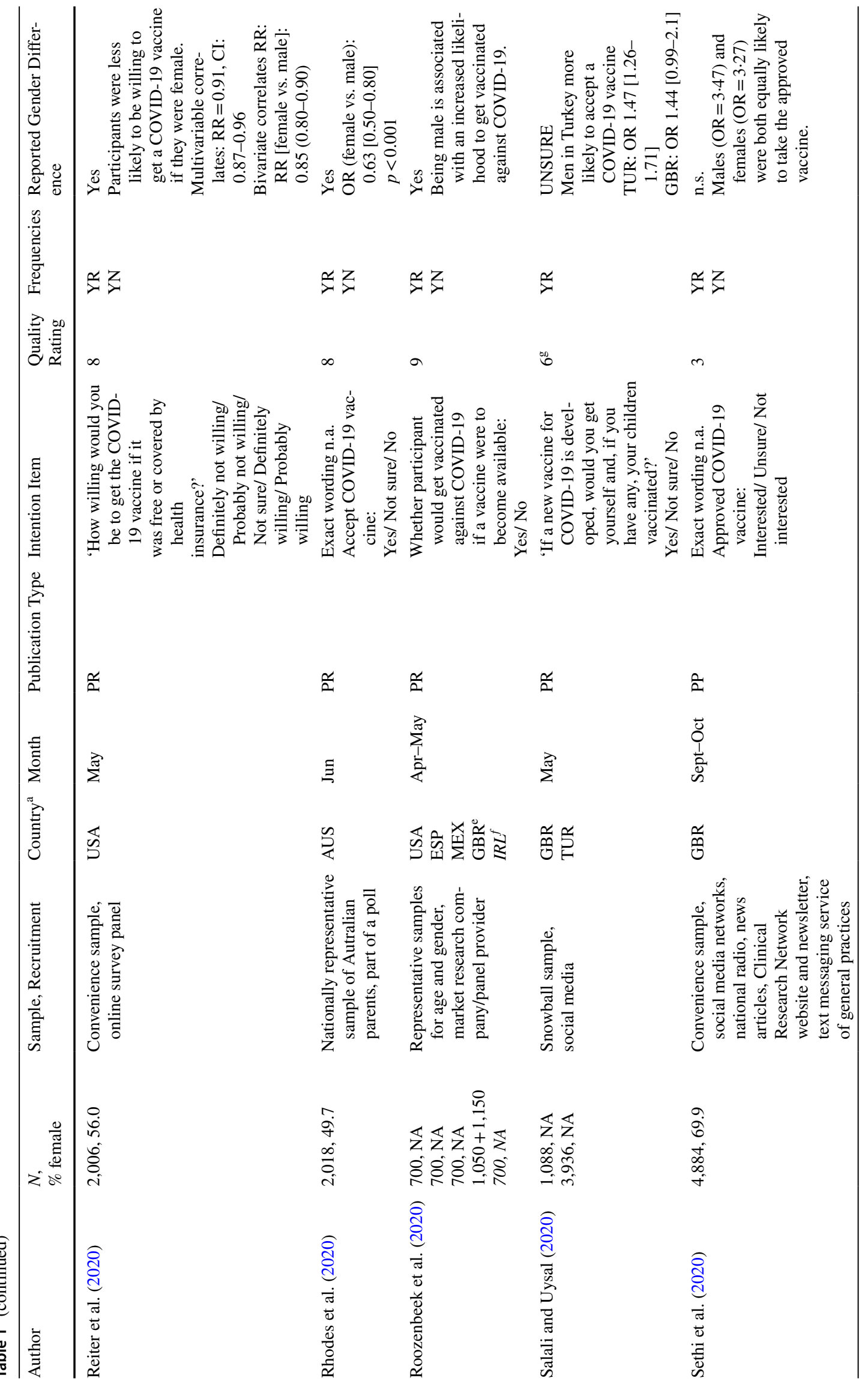




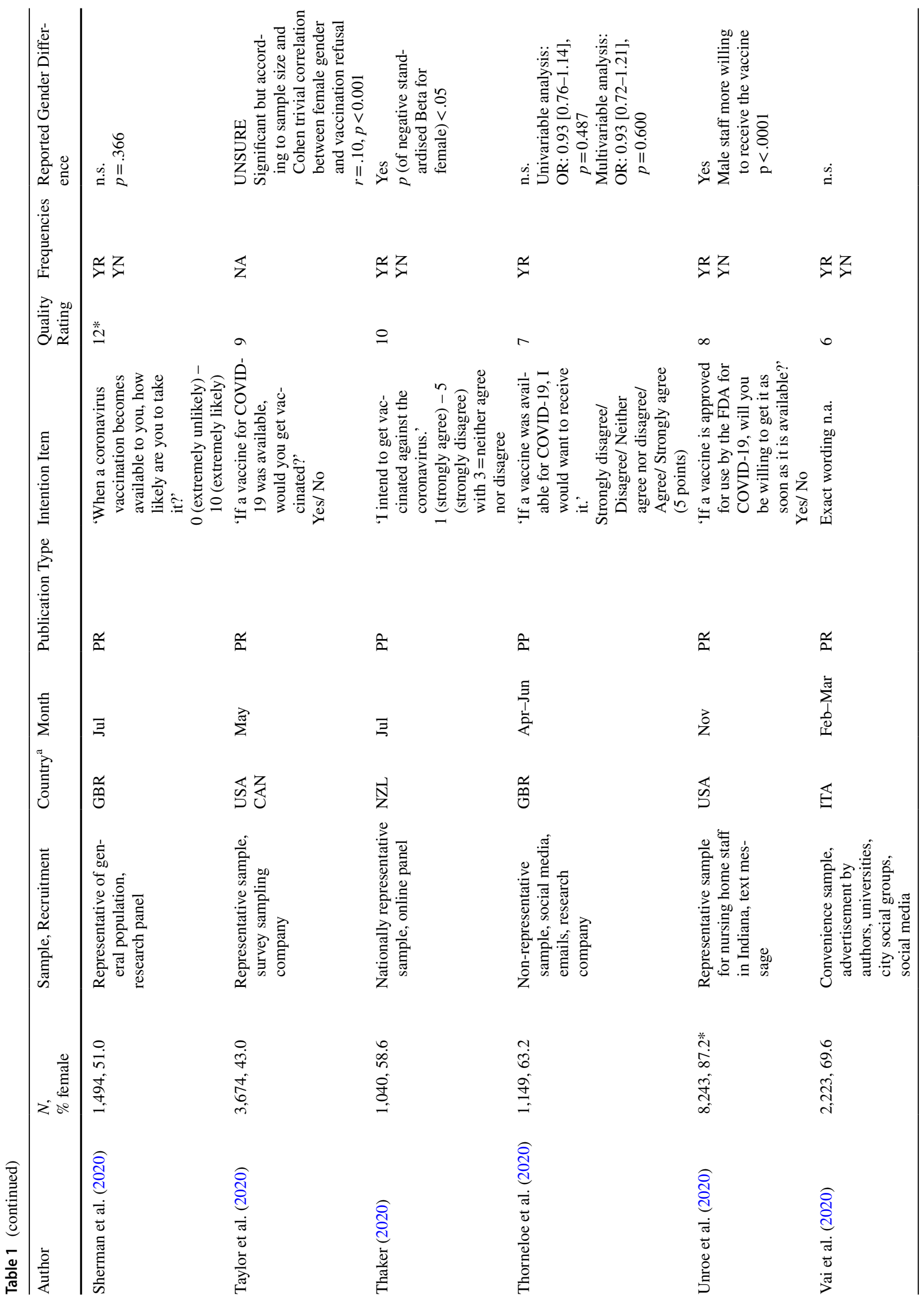




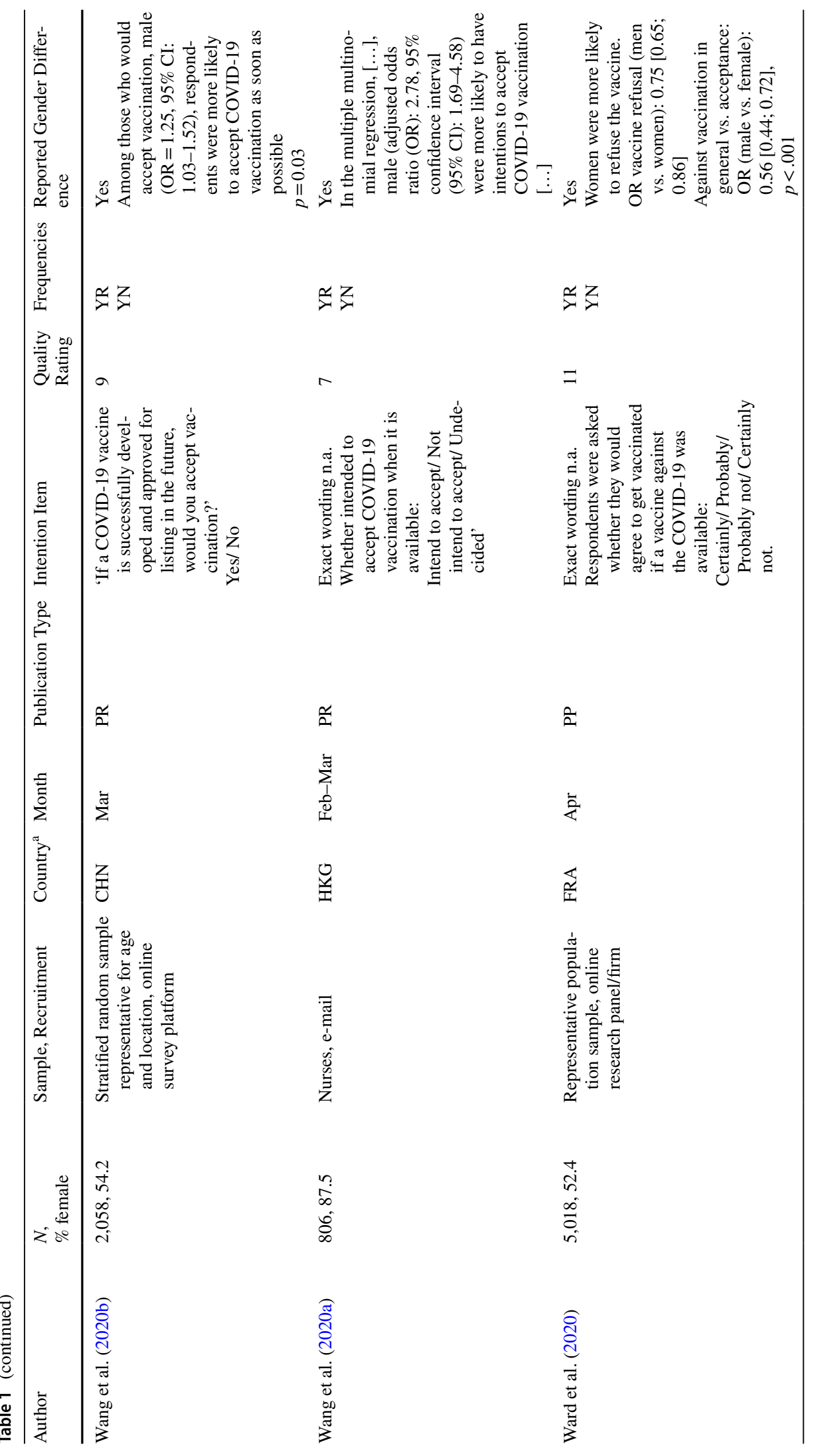




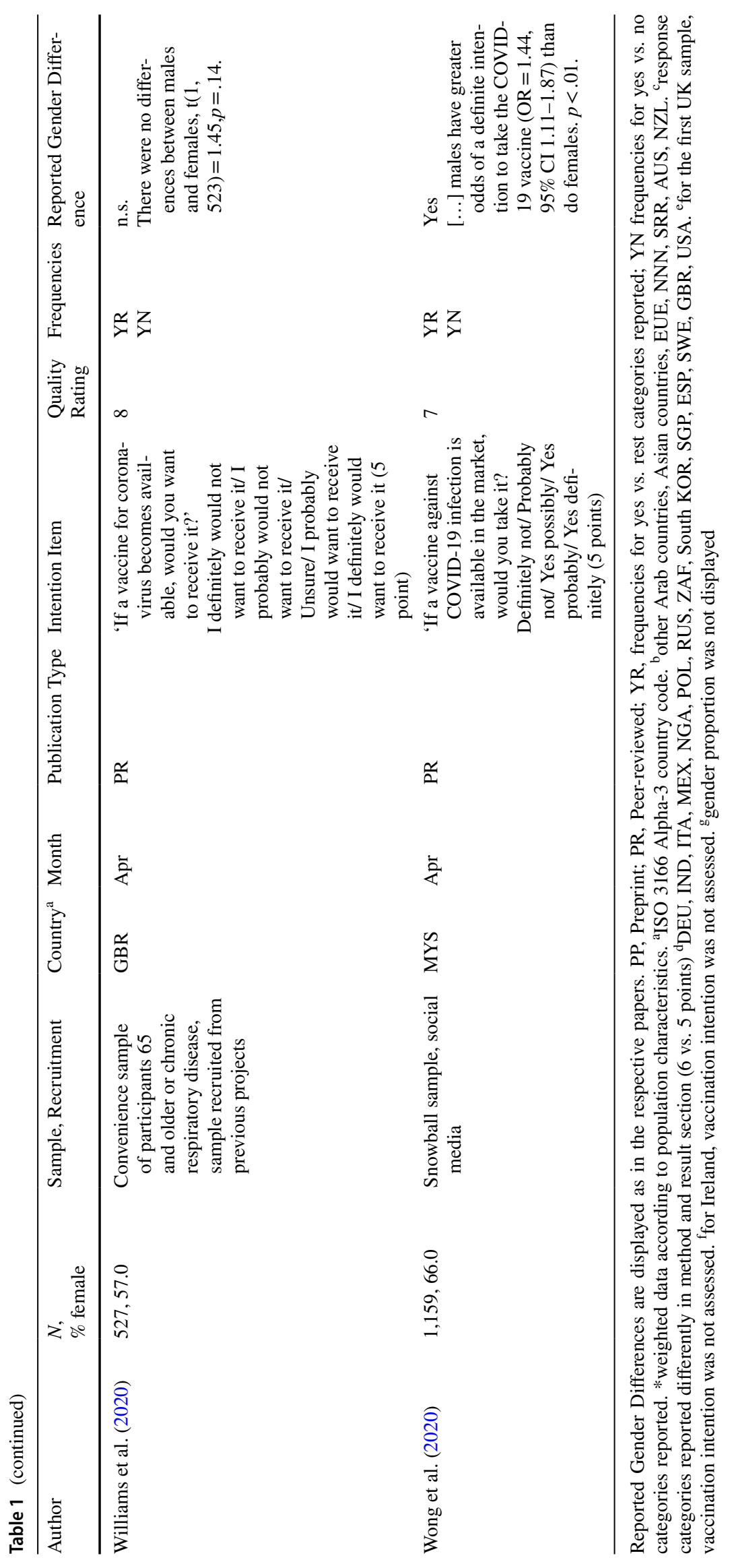


participants with a total of 195,974 people across all 60 studies. The vast majority (70\%) of studies, namely 42 , had sample sizes of over 1,000 participants. Most papers $(n=35)$ were peer reviewed, but a substantial number were preprints $(n=24)$, and one was a report of scientific surveys made accessible online (Perlis et al. 2020). Surveys took place in 40 different countries. Most papers included samples from the USA $(n=22)$, UK $(n=13)$, Italy $(n=5)$, France $(n=5)$ and Australia $(n=4)$. Twenty-three studies took place in Europe exclusively.

Wording of the vaccination intention item was similar across the surveys. Most items asked about 'likelihood', 'intention' or 'willingness' to vaccinate or 'acceptance' of a COVID-19 vaccine. However, response categories varied from two ('yes', 'no') to five or more categories and one with 11 categories (Sherman et al. 2020). Many studies $(n=24)$ explicitly included a 'not sure'/'undecided'/'maybe'response category. We included studies that were conducted from February 2020 (Papagiannis et al. 2020) to November 2020 (Barry et al. 2020). Most studies $(n=15)$ took place in April 2020 (including those studies lasting more than one month), few studies were conducted in February and November ( $n=2$ each). Three studies did not report the time or period of recruitment (Pogue et al. 2020; Al-Mohaithef and Padhi 2020; Lucia et al. 2020). Results of a quality appraisal for the 60 studies are reported in the Supplementary Material.

\section{Gender differences in vaccination intentions}

Thirty-six studies report significant gender differences in vaccination intentions in their result section for the whole sample. Male gender was associated with a greater likelihood of intending to accept a COVID-19 vaccine in 35 studies (58\%). Only one study (Lazarus et al. 2020), reported men to be less likely to intend to accept of the vaccination compared with women. In five studies (Butter et al. 2020; Davis et al. 2020; McAndrew and Allington 2020; Salali and Uysal 2020; Khubchandani et al. 2021) results were not clear because significant gender differences could be found only in some subgroups and analyses but not in others. Most studies recruited only from the general adult population $(n=41)$. Twelve looked exclusively at health care workers and/or health care students (Grech et al. 2020a; Papagiannis et al. 2020; Barry et al. 2020; Lucia et al. 2020; Gadoth et al. 2020; Grech and Gauci 2020; Grech et al. 2020b; Nzaji et al. 2020; Kose et al. 2020; Kwok et al. 2020; Unroe et al. 2020; Wang et al. 2020a). Of those, eight reported significant gender differences $(66.7 \%)$ as can be seen in Table 1. Four studies purposefully oversampled HCWs or key workers (Butter et al. 2020; Detoc et al. 2020; Dror et al. 2020; Grüner and Krüger 2020) to compare their intentions with the general population. Of those, only Butter et al. (2020) analysed gender differences separately for the two groups. They reported a significant association of COVID-19 vaccine hesitancy and being female only for key workers (mainly individuals employed in positions in health care, education and childcare or positions crucial for providing food, necessities and utilities).

\section{Meta-analytic results}

Forty-six papers (77\%) included frequency statistics for the calculation of averaged odds ratios (ORs) or they were provided by the authors upon request. This is noted in Table 1 in the column Frequencies. Roozenbeek et al. (2020) provided us with data from more countries and months than in the original paper which is why we have a larger sample for our own calculations then they did in their paper. ${ }^{2}$ For Sethi et al. (2020), we computed the frequencies for the 'yes'category from the frequencies of the other categories given in the paper. Loomba et al. (2020) conducted their study in the USA and UK but only data for the UK was available for meta-analytic computations. Daly and Robinson (2020) had frequencies for their assessment in April and October. We used data for April after verifying that follow up data for October did not make a big difference for our calculations. We conducted meta-analytic computation of the available data.

Data were available for 141,550 female and male participants, excluding people not identifying as male or female or with missing data. Of those papers not providing frequency statistics $(n=14)$, seven papers $(50.0 \%)$ reported significant gender effects in their results section in favour of men and two papers each found significant effects for one of two subgroups. For the papers with reported or provided frequency statistics this percentage was higher with $60.9 \%$ of the papers $(n=28)$ reporting significant gender effects in favour of men. Mean quality rating of the papers without frequencies was $M=7.92(S D=2.3)$ with six papers (42.9\%) with a rating of nine and higher (up to 12 which was the maximum). Mean quality rating of the papers with frequency statistics provided was $M=8.02(S D=2.19)$ with 18 papers $(39 \%)$ with a rating of nine and higher and three papers with a rating of 12 . Mean quality ratings did not differ, $U=294.00, Z=-0.495, p=0.62$.

Not all of the 46 papers had frequencies broken up into every answer category but summarized over several categories so that absolute 'no'-answers could not be obtained for all of them. We therefore compared 'yes'-answers with the rest-categories, that is, all but the 'yes'-categories, including

\footnotetext{
${ }^{2}$ Additional frequencies were provided for: Australia, China, Germany, Spain, France, Italy, Japan, South Korea, Mexico, Sweden, the UK and USA.
} 


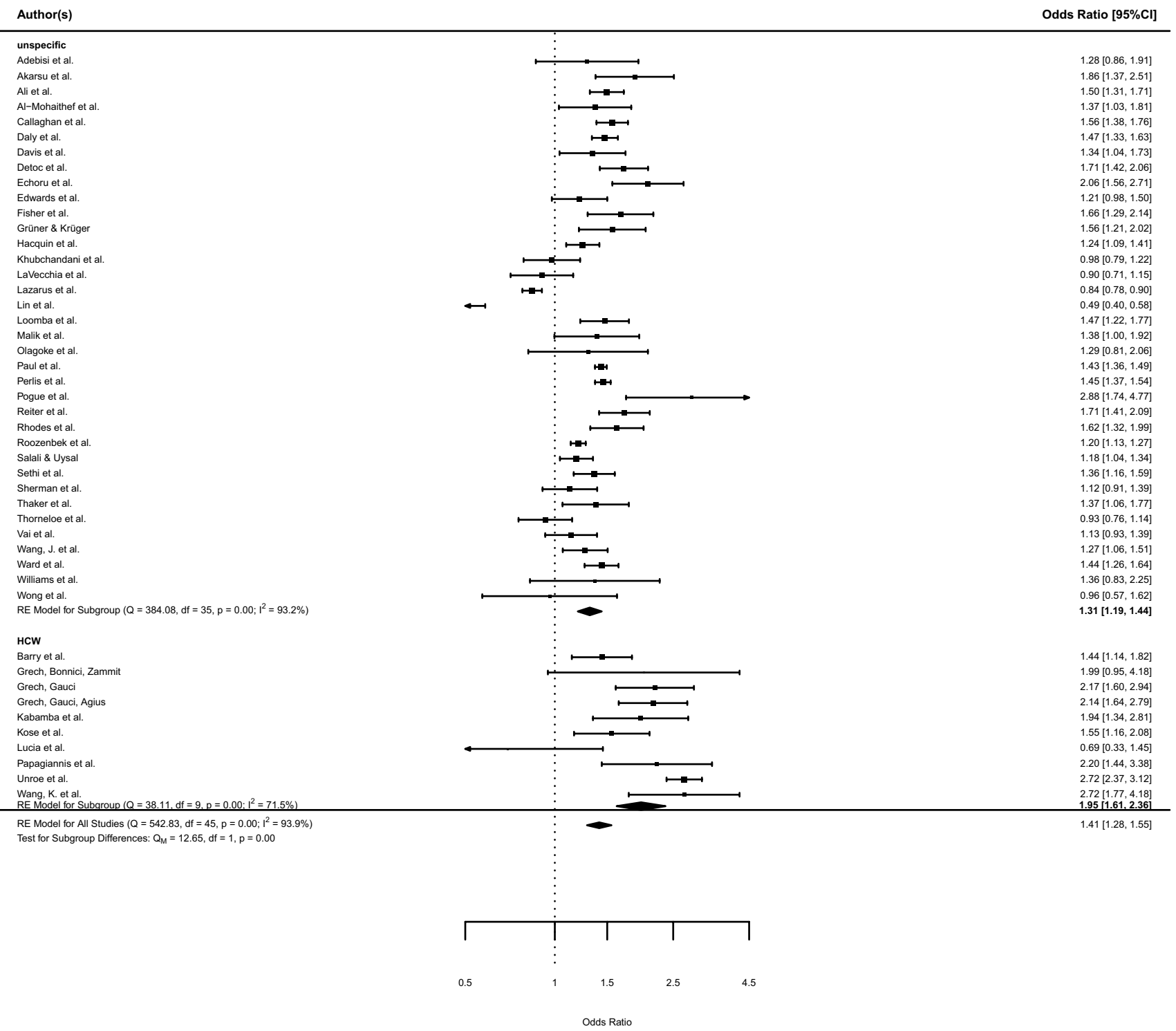

Fig. 2. Forest plot of the odds of men reporting the intention to get vaccinated against COVID-19 compared to the reference group of women in unspecified samples (above) and Health Care Workers
Samples (HCW, below). Results are expressed as odds ratio (OR) and $95 \%$ confidence intervals

et al. 2021; Grüner and Krüger 2020). Model results showed that only the factor $\mathrm{HCW}$ was a significant moderator for the observed study effects, $t=3.51, p=0.001$ (quality: $t=-0.36, p=0.720$; month: $t=0.03, p=0.975)$. The amount of heterogeneity $R^{2}$ accounted for was $25.26 \%$. Subgroup analysis revealed a significant subgroup difference for the yes vs. rest analysis with $Q_{M}=23.65, p=0.00$. Heterogeneity in the HCW subsample was lower than in the other subgroup but substantial in both (see Fig. 2). Averaged odd ratios for the subgroup of HCW was OR 1.79, $95 \%$ CI [1.61, 2.36] vs. OR 1.31, 95\% CI [1.19, 1.44] for the unspecific sample. 


\section{Discussion}

In our systematic review we investigated gender differences in COVID-19 vaccination intentions. In our meta-analysis of averaged odds ratios across all the studies that provided us with the necessary frequency data $(n=46)$ we found an overall significant gender difference with males being on average $41 \%$ more likely to report that they intended to receive a vaccine (rather than being unwilling or undecided) compared with women. Quality ratings of the studies or first month of assessment did not have a significant impact on study effects. Subgroup analyses in response to our moderator analyses revealed that gender effects were even higher among health care workers (HCWs) compared with unspecific samples. However, this result must be interpreted cautiously because in HCW samples gender proportions were highly unbalanced and the number of studies with HCW samples was comparatively small.

Our finding that men showed on average a higher COVID19 vaccination intention supports initial trends indicating systematic gender differences in reviews of COVID-19 vaccination intention (Galanis et al. 2020; Lin et al. 2021; Robinson et al. 2020). They are also in line with research on other vaccinations. For example, a study of vaccination coverage among adolescents found that females had a lower likelihood of being fully vaccinated compared with men (Sakou et al. 2011). Men have also been found to have higher vaccination rates than women in the case of influenza and pandemic influenza vaccinations (Bish et al. 2011; Pulcini et al. 2013; Jiménez-García et al. 2010).

\section{Vaccination intentions and actual vaccination uptake}

In our efforts to compare COVID-19 vaccination intentions with the uptake of COVID-19 vaccinations, the majority of data has not yet been broken down by gender. In the COVID19 Sex-Disaggregated Data Tracker (Global Health 50/50 2021), data only refer to the proportion of men/women in a country among all vaccinated people. This is skewed given that in some countries small numbers of people have been offered the vaccine to date.

There is much less data on the proportion of men and women who have accepted an offer to be vaccinated. In Germany, a representative survey conducted in August 2021 with 4,144 adults, showed that $79 \%$ of men and $73 \%$ of women reported that they have received a first vaccination dose (Huebner and Wagner 2021). In Austria, as of October 10 , among most age groups (55 to over 84 years old), more men than women received a first dose of the COVID-19 vaccine (e.g. $98 \%$ of men vs. $90 \%$ of women among those aged over 84) (Bundesministerium Soziales Gesundheit Pflege und Konsumentenschutz Österreich 2021). Only in two age groups, namely between 15 and 24 years and 45 to 54 years, slightly more women had been vaccinated by mid-October. In the UK, overall $90.1 \%$ of females compared to $87.7 \%$ of males have been vaccinated with at least one dose since the vaccinations started (National Health Service 2021).

Evidence about vaccination uptake among HCWs in the UK and USA support our findings about female HCWs being more hesitant to get vaccinated. In the SIREN study in the UK on 29,378 hospital personnel, male HCWs were significantly more likely to be vaccinated than female HCWs, namely $90.8 \%$ of men vs. $88.1 \%$ of women (Hall et al. 2021). Among members of the Athens Medical Associations, more men $(86.4 \%)$ than women $(83.8 \%)$ were vaccinated. This difference failed to reach significance though. In the USA by July 2021 , in a representative sample of $1,591 \mathrm{HCWs}$, female HCWs were less likely to be vaccinated, with $69 \%$ of female HCWs compared with $79 \%$ of male HCWs being vaccinated (Lazer et al. 2021).

Many of the studies included in this review asked individuals about their intentions to get the vaccine before a vaccine was available. It is well established that intentions do not always materialise into behaviour (Sheeran and Webb 2016). Usually, people are more likely to state they intend to do something and subsequently fail than the other way around. For example, in the field of physical activity, people often intend to exercise but do not always successfully translate this intention (inclined abstainers) into behaviour (Rhodes and de Bruijn 2013). In contrast, COVID-19 vaccine uptake in the UK is currently higher than anticipated, e.g. $64 \%$ of UK adults intended to get the vaccine when surveyed in September/October 2020 (Paul et al. 2020), while over 78.5\% of people have received the first dose of the vaccine one year later (Government UK 2021b).

\section{Individual vs. policy factors}

The fact that vaccination uptake was in most cases higher than indicated by early surveys may be attributable to a number of factors. Thinking of the intention-behaviour gap, a certain proportion of women (but also men) who had expressed low intentions, turned out to be 'disinclined actors', i.e. people who originally did not intend but nevertheless acted on something (Sheeran 2001). Information campaigns and the implementation of roll out may have addressed individual modifiable barriers that underpinned vaccine hesitancy at the time the surveys were conducted. In this respect, it can be considered a success that early data helped policy makers increase uptake and diminish gender disparities. In part, the on average lower intentions stated by women found in our meta-analysis may have been overcome by several factors (especially in high-income 
countries). Rising infections and the associated increased mortality, positive experiences with the COVID-19 vaccination by millions of people and very high initial uptake among high-risk groups positively influencing perceived norms to accept the vaccination may have contributed to this. Another important influence would have been policies around vaccination passports and increased personal freedom.

Regarding current vaccination mandates and policies, no country has a federal vaccination mandate. However, in the USA, many institutions, including universities, hospitals and big companies such as Walmart, require a vaccination by their employees or are about to install a vaccination mandate (Hals 2021). Additionally, the new Biden-Harris Administration will demand vaccination requirements for staff within all Medicare and Medicaid-certified facilities (Centers for Medicare and Medicaid Services 2021). In the UK, by 11 November 2021, care home staff must be fully vaccinated (Government UK 2021a). In Austria, similar to the USA, certain institutions in certain regions are allowed to and do require a COVID-19 vaccination, especially for new staff members (Tempfer 2021). In Germany, legislation to make COVID-19 vaccinations mandatory for health care workers has recently been passend and will come into effect in March 2022 (Bundesgesundheitsministerium 2021). A vaccine mandate for the general German population is also being discussed. These differences in actual vaccination policies and next to that different ways of promoting the vaccines and communicating vaccination information may play an important role in convincing vaccine non-intenders to get vaccinated.

\section{Limitations}

Some limitations have to be addressed. We were not able to compare vaccination intentions in men and women among subgroups, for example, age groups or education levels. Therefore, we cannot rule out that our findings may be more or less pronounced in certain subgroups. We used a dichotomous format in our analyses; therefore, we were not able to see if women were maybe more hesitant but not strongly rejecting of the vaccine. Additional analyses distinguishing between people answering 'yes' or 'no' to vaccine acceptance with certainty and those being 'unsure' revealed that a greater proportion of women reported being 'unsure'. Respondents being unsure might have been more easily convinced to take the vaccine once the campaigns started in comparison with those having had a strong negative opinion. In addition, meta-analytic calculations have not been adjusted for potential confounders such as country or study design. Accordingly, comparability between studies included in the meta-analysis is limited which is reflected in a rather high heterogeneity score.

Our search was conducted from November 2020 to January 2021 and therefore our findings do not incorporate if vaccination intentions changed from then on.

\section{Implications for policy and practice}

Even if a large fraction of people - at least in high-income countries - is vaccinated already, the number of those who are not remains high. In the USA by the end of October $2021,44 \%$ of the population were not fully vaccinated, in the UK 33\% and in Germany 34\% (Ritchie et al. 2021). In most countries where availability of vaccines is sufficient, people who had a high intention should be vaccinated by now. It might be necessary to focus on policy measures rather than individual psychological factors to reach the last share of unvaccinated people. It would be interesting to compare the policy measures in their effectiveness to convince still unvaccinated people in different countries. In the field of HCW, the next step is to find out how to convince hesitant women (and men) to get the vaccine.

Supplementary Information The online version contains supplementary material available at https://doi.org/10.1007/s10389-021-01677-w.

Authors' contributions MS and CvW provided the research idea. SZ $\&$ CF undertook data collection, analyses and wrote the detailed draft of the manuscript. LA assisted in the analyses. MS extended and put together the manuscript. $\mathrm{CvW}$ and $\mathrm{AF}$ contributed to the writing and reviewing of the manuscript. All authors reviewed and approved the final version of the manuscript.

Funding Open Access funding enabled and organized by Projekt DEAL.

Availability of data and material The data that support the findings of this study are available from the corresponding author upon reasonable request.

Code availability Not applicable.

\section{Declarations}

Conflict of interest The authors declare that there is no financial or non-financial conflict of interest.

Ethics approval Not applicable.

Consent to participate Not applicable.

Consent for publication Not applicable.

Open Access This article is licensed under a Creative Commons Attribution 4.0 International License, which permits use, sharing, adaptation, distribution and reproduction in any medium or format, as long 
as you give appropriate credit to the original author(s) and the source, provide a link to the Creative Commons licence, and indicate if changes were made. The images or other third party material in this article are included in the article's Creative Commons licence, unless indicated otherwise in a credit line to the material. If material is not included in the article's Creative Commons licence and your intended use is not permitted by statutory regulation or exceeds the permitted use, you will need to obtain permission directly from the copyright holder. To view a copy of this licence, visit http://creativecommons.org/licenses/by/4.0/.

\section{References}

Adebisi YA, Alaran AJ, Bolarinwa OA, Akande-Sholabi W, LuceroPrisno DE (2020) When it is available, will we take it? Public perception of hypothetical COVID-19 vaccine in Nigeria. medRxiv. https://doi.org/10.1101/2020.09.24.20200436

Akarsu B, Canbay Özdemir D, Ayhan Baser D, Aksoy H, Fidancı İ, Cankurtaran M (2020) While studies on COVID-19 vaccine is ongoing, the public's thoughts and attitudes to the future COVID-19 vaccine. Int J Clin Pract e13891. https://doi.org/10. 1111/ijcp.13891

Ali KF, Whitebridge S, Jamal MH, Alsafy M, Atkin SL (2020) Perceptions, knowledge, and behaviors related to COVID-19 among social media users: cross-sectional study. J Med Internet Res 22:e19913. https://doi.org/10.2196/19913

Al-Mohaithef M, Padhi BK (2020) Determinants of COVID-19 vaccine acceptance in Saudi Arabia: a web-based national survey. J Multidiscip Healthc 13:1657-1663 https://doi.org//JMDH.S276771

Barry M, Temsah M-H, Alhuzaimi A, Alamro N, Al-Eyadhy A, Aljamaan F et al (2020) COVID-19 vaccine confidence and hesitancy among healthcare workers: a cross-sectional survey from a MERS-CoV experienced nation. medRxiv. https://doi.org/10. 1101/2020.12.09.20246447

Bish A, Yardley L, Nicoll A, Michie S (2011) Factors associated with uptake of vaccination against pandemic influenza: a systematic review. Vaccine. 29:6472-6484. https://doi.org/10.1016/j.vacci ne.2011.06.107

Bramer WM, Giustini D, de Jonge GB, Holland L, Bekhuis T (2016) De-duplication of database search results for systematic reviews in EndNote. JMLA 104:240-243. https://doi.org/10.3163/15365050.104.3.014

Bundesgesundheitsministerium (2021) Einrichtungsbezogene Impflicht kommt: Bundestag und Bundesrat beschließen "Gesetz zur Stärkung der Impfprävention gegen Covid-19". Available from https://www.bundesgesundheitsministerium.de/ministerium/ meldungen/einrichtungsbezogene-impfpflicht-kommt.html. Accessed 29 Dec 2021

Bundesministerium Soziales Gesundheit Pflege und Konsumentenschutz Österreich (2021) Corona-Schutzimpfung in Österreich. Available from: https://info.gesundheitsministerium.at/. Accessed 11 Oct 2021

Butter S, McGlinchey E, Berry E, Armour C (2020) Psychological, social, and situational factors associated with COVID-19 vaccination intentions: a study of UK key workers and non-key workers. PsyArXiv. https://doi.org/10.31234/osf.io/cfp3r

Callaghan T, Moghtaderi A, Lueck JA, Hotez PJ, Strych U, Dor A et al (2020) Correlates and disparities of COVID-19 vaccine hesitancy. SSRN. https://doi.org/10.2139/ssrn.3667971

Centers for Medicare \& Medicaid Services (2021) Biden-Harris administration to expand vaccination requirements for health care settings. Available from: https://www.cms.gov/newsroom/press-relea ses/biden-harris-administration-expand-vaccination-requiremen ts-health-care-settings. Accessed 29 Oct 2021

Daly M, Robinson E (2020) Willingness to vaccinate against COVID19 in the US: longitudinal evidence from a nationally representative sample of adults from April-October 2020. medRxiv. https:// doi.org/10.1101/2020.11.27.20239970

Davis MM, Zickafoose JS, Halvorson AE, Patrick S (2020) Parents' likelihood to vaccinate their children and themselves against COVID-19. medRxiv. https://doi.org/10.1101/2020.11.10.20228 759

Detoc M, Bruel S, Frappe P, Tardy B, Botelho-Nevers E, GagneuxBrunon A (2020) Intention to participate in a COVID-19 vaccine clinical trial and to get vaccinated against COVID-19 in France during the pandemic. Vaccine 38:7002-7006. https://doi.org/10. 1016/j.vaccine.2020.09.041

Dror AA, Eisenbach N, Taiber S, Morozov NG, Mizrachi M, Zigron A et al (2020) Vaccine hesitancy: the next challenge in the fight against COVID-19. Eur J Epidemiol 35:775-779. https://doi.org/ 10.1007/s10654-020-00671-y

Earnshaw VA, Eaton LA, Kalichman SC, Brousseau NM, Hill EC, Fox AB (2020) COVID-19 conspiracy beliefs, health behaviors, and policy support. Transl Behav Med 10:850-856. https://doi.org/ 10.1093/tbm/ibaa090

Echoru I, Ajambo PD, Bukenya EM (2020) Acceptance and risk perception of COVID-19 vaccine in Uganda: a cross sectional study in Western Uganda. https://doi.org/10.21203/rs.3.rs-78780/v1

Edwards B, Biddle N, Gray M, Sollis K (2020) COVID-19 vaccine hesitancy and resistance: correlates in a nationally representative longitudinal survey of the Australian population. PloS one 16:e24889. https://doi.org/10.1371/journal.pone.0248892

Faasse K, Newby J (2020) Public perceptions of COVID-19 in Australia: perceived risk, knowledge, health-protective behaviors, and vaccine intentions. Front Psychol 11:551004. https://doi. org/10.3389/fpsyg.2020.551004

Fisher KA, Bloomstone SJ, Walder J, Crawford S, Fouayzi H, Mazor KM (2020) Attitudes toward a potential SARS-CoV-2 vaccine: a survey of U.S. adults. Ann Intern Med 173:964-973. https:// doi.org/10.7326/m20-3569

Gadoth A, Halbrook M, Martin-Blais R, Gray AN, Tobin NH, Ferbas $\mathrm{KG}$ et al (2020) Assessment of COVID-19 vaccine acceptance among healthcare workers in Los Angeles. medRxiv. https:// doi.org/10.1101/2020.11.18.20234468

Galanis PA, Vraka I, Fragkou D, Bilali A, Kaitelidou D (2020) Intention of health care workers to accept COVID-19 vaccination and related factors: a systematic review and meta-analysis. medRxiv. https://doi.org/10.1101/2020.12.08.20246041

Global Health 50/50 (2021) The COVID-19 sex-disaggregated data tracker. Available from: https://globalhealth5050.org/the-sexgender-and-covid-19-project/the-data-tracker/. Accessed 05 Nov 2021

Government UK (2021a) Coronavirus (COVID-19) vaccination of people working or deployed in care homes: operational guidance. Available from: https://www.gov.uk/government/ publications/vaccination-of-people-working-or-deployed-incare-homes-operational-guidance/coronavirus-covid-19-vacci nation-of-people-working-or-deployed-in-care-homes-opera tional-guidance. Accessed 25 Oct 2021

Government UK (2021b) Vaccinations in United Kingdom. Available from: https://coronavirus.data.gov.uk/details/vaccinations. Accessed 11 Oct 2021

Grech V, Gauci C (2020) Vaccine hesitancy in the University of Malta Faculties of health sciences, dentistry and medicine vis-à-vis influenza and novel COVID-19 vaccination. Early Hum Dev 105258. https://doi.org/10.1016/j.earlhumdev.2020.105258

Grech V, Bonnici J, Zammit D (2020a) Vaccine hesitancy in Maltese family physicians and their trainees Vis-à-Vis influenza and novel 
COVID-19 vaccination. Early Hum Dev 105259. https://doi.org/ 10.1016/j.earlhumdev.2020.105259

Grech V, Gauci C, Agius S (2020b) Vaccine hesitancy among Maltese healthcare workers toward influenza and novel COVID-19 vaccination. Early Hum Dev 105213. https://doi.org/10.1016/j.earlh umdev.2020.105213

Grüner S, Krüger F (2020) The intention to be vaccinated against COVID-19: stated preferences before vaccines were available. Appl Econ Lett 28:1847-1852. https://doi.org/10.1080/13504 851.2020 .1854445

Guidry JPD, Laestadius LI, Vraga EK, Miller CA, Perrin PB, Burton CW et al (2021) Willingness to get the COVID-19 vaccine with and without emergency use authorization. Am J Infect Control 49:137-142. https://doi.org/10.1016/j.ajic.2020.11.018

Hacquin A-S, Altay S, de Araujo E, Chevallier C, Mercier H (2020) Sharp rise in vaccine hesitancy in a large and representative sample of the French population: reasons for vaccine hesitancy. PsyArXiv. https://doi.org/10.31234/osf.io/r8h6z

Hall VJ, Foulkes S, Saei A, Andrews N, Oguti B, Charlett A et al (2021) COVID-19 vaccine coverage in health-care workers in England and effectiveness of BNT162b2 mRNA vaccine against infection (SIREN): a prospective, multicentre, cohort study. Lancet 397:1725-1735. https://doi.org/10.1016/S0140-6736(21) 00790-X

Hals T (2021) Factbox: COVID-19 and the U.S. courts: challenges to vaccine requirements. Available from: https://www.reuters.com/ world/the-great-reboot/covid-19-us-courts-challenges-vaccinerequirements-2021-09-29/. Accessed 25 Oct 2021

Head KJ, Kasting ML, Sturm LA, Hartsock JA, Zimet GD (2020) A national survey assessing SARS-CoV-2 vaccination intentions: implications for future public health communication efforts. Sci Commun 42:698-723. https://doi.org/10.1177/1075547020 960463

Huebner M, Wagner GG (2021) Unterschiede in COVID19-Impfquoten und in den Gründen einer Nichtimpfung nach Geschlecht, Alter, Bildung und Einkommen: Deutsches Institut für Wirtschaftsforschung. Available from: https://www.econstor. eu/handle/10419/243197. Accessed 29 Oct 2021

IntHout J, Ioannidis JP, Borm GF (2014) The Hartung-Knapp-SidikJonkman method for random effects meta-analysis is straightforward and considerably outperforms the standard DerSimonianLaird method. BMC Med Res Methodol 14:1-12. https://doi. org/10.1186/1471-2288-14-25

Jackson D, Law M, Rücker G, Schwarzer G (2017) The HartungKnapp modification for random-effects meta-analysis: a useful refinement but are there any residual concerns? Stat Med 36:3923-3934. https://doi.org/10.1002/sim.7411

Jiménez-García R, Hernández-Barrera V, de Andres AL, JimenezTrujillo I, Esteban-Hernández J, Carrasco-Garrido P (2010) Gender influence in influenza vaccine uptake in Spain: time trends analysis (1995-2006). Vaccine 28:6169-6175. https:// doi.org/10.1016/j.vaccine.2010.07.029

Khubchandani J, Sharma S, Price JH, Wiblishauser MJ, Sharma M, Webb FJ (2021) COVID-19 vaccination hesitancy in the United States: a rapid national assessment. J Community Health 46:270-277. https://doi.org/10.1007/s10900-020-00958-x

Kose S, Mandiracioglu A, Sahin S, Kaynar T, Karbus O, Ozbel Y (2020) Vaccine hesitancy of the COVID-19 by health care personnel. Int J Clin Pract 75:e13917. https://doi.org/10.1111/ijcp. 13917

Kwok KO, Li KK, Wei WI, Tang KH, Wong SYS, Lee SS (2020) Are we ready when COVID-19 vaccine is available? Study on nurses' vaccine hesitancy in Hong Kong. medRxiv. https://doi. org/10.1101/2020.07.17.20156026

La Vecchia C, Negri E, Alicandro G, Scarpino V (2020) Attitudes towards influenza vaccine and a potential COVID-19 vaccine in Italy and differences across occupational groups, September 2020. Med Lav 111:445-8. https://doi.org/10.23749/mdl. v111i6.10813

Lazarus JV, Ratzan SC, Palayew A, Gostin LO, Larson HJ, Rabin K et al (2020) A global survey of potential acceptance of a COVID19 vaccine. Nat Med 27:225-228. https://doi.org/10.1038/ s41591-020-1124-9

Lazer D, Qu H, Ognyanova K, Perlis RH, Baum MA, Druckman J et al (2021) The COVID states project: a 50-state COVID survey report \#62: COVID-19 vaccine attitudes among healthcare workers. Available from: http://news.northeastern.edu/uploads/ COVID19\%20CONSORTIUM\%20REPORT\%2062\%20HCW\% 20August\%202021.pdf. Accessed 29 Oct 2021

Lin Y, Hu Z, Zhao Q, Alias H, Danaee M, Wong LP (2020) Understanding COVID-19 vaccine demand and hesitancy: a nationwide online survey in China. PLOS Neglect Trop D 14:e0008961. https://doi.org/10.1371/journal.pntd.0008961

Lin C, Tu P, Beitsch LM (2021) Confidence and receptivity for COVID-19 vaccines: a rapid systematic review. Vaccines. 9:16. https://doi.org/10.3390/vaccines9010016

Loomba S, de Figueiredo A, Piatek SJ, de Graaf K, Larson HJ (2020) Measuring the impact of exposure to COVID-19 vaccine misinformation on vaccine intent in the UK and US. medRxiv. https:// doi.org/10.1101/2020.10.22.20217513

Lucia VC, Kelekar A, Afonso NM (2020) COVID-19 vaccine hesitancy among medical students. J Public Health 43:445-449. https://doi. org/10.1093/pubmed/fdaa230

Malik AA, McFadden SM, Elharake J, Omer SB (2020) Determinants of COVID-19 vaccine acceptance in the US. EClinMed. 26:100495. https://doi.org/10.1016/j.eclinm.2020.100495

McAndrew S, Allington D (2020) Mode and frequency of Covid-19 information updates, political values, and future Covid-19 vaccine attitudes. PsyArXiv. https://doi.org/10.31234/osf.io/j7srx

Murphy J, Vallières F, Bentall RP, Shevlin M, McBride O, Hartman TK et al (2020) Preparing for a COVID-19 vaccine: identifying and psychologically profiling those who are vaccine hesitant or resistant in two general population samples. PsyArxiv. https://doi. org/10.31234/osf.io/pev2b

National Health Service (2021) COVID-19 vaccination statistics: week ending Sunday 3rd October 2021. Available from: https://www. england.nhs.uk/statistics/wp-content/uploads/sites/2/2021/10/ COVID-19-weekly-announced-vaccinations-07-October-2021. pdf. Accessed 11 Oct 2021

Neumann-Böhme S, Varghese NE, Sabat I, Barros PP, Brouwer W, van Exel J et al (2020) Once we have it, will we use it? A European survey on willingness to be vaccinated against COVID19. Eur J Health Econ 21:977-982. https://doi.org/10.1007/ s10198-020-01208-6

Nzaji MK, Ngombe LK, Mwamba GN, Ndala DBB, Miema JM, Lungoyo CL et al (2020) Acceptability of vaccination against COVID19 among healthcare workers in the Democratic Republic of the Congo. Pragmat Obs Res 11:103-109. https://doi.org/10.2147/ por.S271096

Olagoke AA, Olagoke OO, Hughes AM (2020) Intention to vaccinate against the novel 2019 coronavirus disease: the role of health locus of control and religiosity. J Relig Health 60:65-85. https:// doi.org/10.1007/s10943-020-01090-9

Papagiannis D, Malli F, Raptis DG, Papathanasiou IV, Fradelos EC, Daniil Z et al (2020) Assessment of knowledge, attitudes, and practices towards new coronavirus (SARS-CoV-2) of health care professionals in Greece before the outbreak period. Int J Environ Res 17:4925. https://doi.org/10.3390/ijerph17144925

Paul E, Steptoe A, Fancourt D (2020) Anti-vaccine attitudes and risk factors for not agreeing to vaccination against COVID-19 amongst 32,361 UK adults: Implications for public health communications. Available at SSRN 3716874. https://doi.org/10.2139/ssrn.3716874 
Perlis RH, Lazer D, Ognyanova K, Baum M, Santillana M, Druckman $\mathrm{J}$ et al (2020) The state of the nation: a 50-state covid-19 survey report\# 9: will Americans vaccinate themselves and their children against COVID-19? Available from: https://www.kateto.net/covid 19/COVID19\%20CONSORTIUM\%20REPORT\%209\%20VAC CINES\%20AUGUST\%202020.pdf. Accessed 12 Feb 2021

Pogue K, Jensen JL, Stancil CK, Ferguson DG, Hughes SJ, Mello EJ et al (2020) Influences on attitudes regarding potential COVID-19 vaccination in the United States. Vaccines 8:582. https://doi.org/ $10.3390 /$ vaccines 8040582

Prati G (2020) Intention to receive a vaccine against SARS-CoV-2 in Italy and its association with trust, worry and beliefs about the origin of the virus. Health Educ Res 35:505-511. https://doi.org/ 10.1093/her/cyaa043

Pulcini C, Massin S, Launay O, Verger P (2013) Factors associated with vaccination for hepatitis $\mathrm{B}$, pertussis, seasonal and pandemic influenza among French general practitioners: a 2010 survey. Vaccine 31:3943-3949. https://doi.org/10.1016/j.vaccine.2013. 06.039

Qiao S, Tam CC, Li X (2020) Risk exposures, risk perceptions, negative attitudes toward general vaccination, and COVID-19 vaccine acceptance among college students in South Carolina. medRxiv. https://doi.org/10.1101/2020.11.26.20239483

Reiter PL, Pennell ML, Katz ML (2020) Acceptability of a COVID19 vaccine among adults in the United States: how many people would get vaccinated? Vaccine 38:6500-6507. https://doi.org/10. 1016/j.vaccine.2020.08.043

Rhodes RE, de Bruijn G-J (2013) How big is the physical activity intention-behaviour gap? A meta-analysis using the action control framework. Br J Health Psychol 18:296-309. https://doi.org/ 10.1111/bjhp.12032

Rhodes A, Hoq M, Measey MA, Danchin M (2020) Intention to vaccinate against COVID-19 in Australia. Lancet Infect Dis 21:E110. https://doi.org/10.1016/s1473-3099(20)30724-6

Riley RD, Higgings JP, Deeks JJ (2011) Interpretation of random effects meta-analyses. BMJ 342:d549. https://doi.org/10.1136/ bmj.d549

Ritchie H, Mathieu E, Rhodés-Guirao L, Appel C, Giattino C, OrtizOspina E et al (2021) Coronavirus pandemic (COVID-19). Available from: https://ourworldindata.org/coronavirus. Accessed 20 Oct 2021

Robinson E, Jones A, Daly M (2020) International estimates of intended uptake and refusal of COVID-19 vaccines: a rapid systematic review and meta-analysis of large nationally representative samples. medRxiv. https://doi.org/10.1101/2020.12.01.20241 729

Roozenbeek J, Schneider CR, Dryhurst S, Kerr J, Freeman ALJ, Recchia G et al (2020) Susceptibility to misinformation about COVID-19 around the world. R Soc Open Sci 7:201199. https:// doi.org/10.1098/rsos.201199

Sakou II, Tsitsika AK, Papaevangelou V, Tzavela EC, Greydanus DE, Tsolia MN (2011) Vaccination coverage among adolescents and risk factors associated with incomplete immunization. Eur J Pediatr 170:1419-1426. https://doi.org/10.1007/s00431-011-1456-z

Salali GD, Uysal MS (2020) COVID-19 vaccine hesitancy is associated with beliefs on the origin of the novel coronavirus in the UK and Turkey. Psychol Med 1-3. https://doi.org/10.1017/s0033 291720004067

Sethi S, Kumar A, Shaikh M, Hall CA, Kirk JM, Moss P et al (2020) The uptake study: insights and beliefs of the UK population on vaccines during the COVID-19 pandemic. Available at SSRN 3723667. https://doi.org/10.2139/ssrn.3723667

Sheeran P (2001) Intention-behavior relations: a conceptual and empirical review. Eur rev. Soc Psychol 1-36. https://doi.org/10. 1002/0470013478.ch1
Sheeran P, Webb TL (2016) The intention-behavior gap. Soc Psychol Compass 10:503-518. https://doi.org/10.1111/spc3.12265

Sherman SM, Smith LE, Sim J, Amlôt R, Cutts M, Dasch H et al (2020) COVID-19 vaccination intention in the UK: results from the COVID-19 vaccination acceptability study (CoVAccS), a nationally representative cross-sectional survey. Hum Vaccin Immunother 17:1612-1621. https://doi.org/10.1080/21645515. 2020.1846397

Taylor S, Landry CA, Paluszek MM, Groenewoud R, Rachor GS, Asmundson GJG (2020) A proactive approach for managing COVID-19: the importance of understanding the motivational roots of vaccination hesitancy for SARS-CoV2. Front Psychol 11:575950. https://doi.org/10.3389/fpsyg.2020.575950

Tempfer P (2021) Impflicht wird immer plausibler. Wiener Zeitung. Available from: https://www.wienerzeitung.at/nachrichten/polit ik/oesterreich/2115298-Impfpflicht-wird-immer-plausibler.html. Accessed 25 Oct 2021

Thaker J (2020) Planning for a COVID-19 vaccination campaign: the role of social norms, trust, knowledge, and vaccine attitudes. PsyArXiv. https://doi.org/10.31234/osf.io/q8mz6

Thorneloe R, Wilcockson H, Lamb M, Jordan CH, Arden M (2020) Willingness to receive a COVID-19 vaccine among adults at high-risk of COVID-19: a UK-wide survey. PsyArXiv. https:// doi.org/10.31234/osf.io/fs9wk

Unroe KT, Evans R, Weaver L, Rusyniak D, Blackburn J (2020) Willingness of long-term care staff to receive a COVID-19 vaccine: a single state survey. J Am Geriatr Soc 69:593-599. https://doi. org/10.1111/jgs. 17022

Vai B, Cazzetta S, Ghiglino D, Parenti L, Saibene G, Toti M et al (2020) Risk perception and media in shaping protective behaviors: insights from the early phase of COVID-19 Italian outbreak. Front Psychol 11:563426. https://doi.org/10.3389/fpsyg.2020. 563426

Viechtbauer W (2010) Conducting meta-analyses in R with the metafor package. J Stat Softw 36:1-48. https://doi.org/10.18637/jss. v036.i03

Wang K, Wong ELY, Ho KF, Cheung AWL, Chan EYY, Yeoh EK et al (2020a) Intention of nurses to accept coronavirus disease 2019 vaccination and change of intention to accept seasonal influenza vaccination during the coronavirus disease 2019 pandemic: a cross-sectional survey. Vaccine 38:7049-7056. https://doi.org/ 10.1016/j.vaccine.2020.09.021

Wang J, Jing R, Lai X, Zhang H, Lyu Y, Knoll MD et al (2020b) Acceptance of COVID-19 vaccination during the COVID-19 pandemic in China. Vaccines 8:482. https://doi.org/10.3390/vacci nes8030482

Ward JK, Alleaume C, Peretti-Watel P (2020) The French public's attitudes to a future COVID-19 vaccine: the politicization of a public health issue. Soc Sci Med 265:113414. https://doi.org/10. 1016/j.socscimed.2020.113414

Webb TL, Sheeran P (2006) Does changing behavioral intentions engender behavior change? A meta-analysis of the experimental evidence. Psychol Bull 132:249-268. https://doi.org/10.1037/ 0033-2909.132.2.249

Weber RE, Bender JK, Abu Sin M, Eckmanns T, Werner G (2021) Eigenschaften, Häufigkeit und Verbreitung von Vancomycinresistenten Enterokokken in Deutschland - Update 2019/2020. Epidemiologisches Bulletin 27:32-42. https://doi.org/10.25646/ 8710

WHO (2021) WHO corona disease (COVID-19) Dashboard. Available from: https://covid19.who.int/. Accessed 05 Nov 2021

Williams L, Gallant AJ, Rasmussen S, Brown Nicholls LA, Cogan N, Deakin K et al (2020) Towards intervention development to increase the uptake of COVID-19 vaccination among those at high risk: outlining evidence-based and theoretically informed 
future intervention content. Br J Health Psychol 25:1039-1054. https://doi.org/10.1111/bjhp.12468

Wong LP, Alias H, Wong PF, Lee HY, AbuBakar S (2020) The use of the health belief model to assess predictors of intent to receive the COVID-19 vaccine and willingness to pay. Hum Vaccin Immunother 16:2204-2214. https://doi.org/10.1080/21645515.2020. 1790279
Zimmer C, Corum J, Wee S-L (2021) Coronavirus Vaccine Tracker. Available from: https://www.nytimes.com/interactive/2020/scien ce/coronavirus-vaccine-tracker.html. Accessed 12 Feb 2021

Publisher's note Springer Nature remains neutral with regard to jurisdictional claims in published maps and institutional affiliations. 